\title{
New Evidence of the Existence of Associative Elements of Water (Clusters)
}

\author{
Ignat Ignatov $^{1^{*}} \quad$ Oleg Mosin ${ }^{2}$ \\ 1. Scientific Research Center of Medical Biophysics (SRCMB), \\ N. Kopernik Street, 32, Sofia 1111, Bulgaria \\ 2. Biotechnology Department, Moscow State University of Applied Biotechnology, \\ Talalikhina Street, 33, Moscow 109316, Russian Federation
}

\begin{abstract}
In this review it is reported about new data on the structure of intermolecular water cyclic associates (clusters) with general formula $\left(\mathrm{H}_{2} \mathrm{O}\right)_{n}$ and their charged ionic clusters $\left[\mathrm{H}^{+}\left(\mathrm{H}_{2} \mathrm{O}\right)_{n}\right]^{+}$and $\left[\mathrm{OH}^{-}\left(\mathrm{H}_{2} \mathrm{O}\right)_{n}\right]^{-}$by means of computer modeling and spectroscopy methods as ${ }^{1} \mathrm{H}-\mathrm{NMR}$, IR-spectroscopy, NES, DNES, EXAFS-spectroscopy, X-Ray and neurons diffraction. The computer calculation of polyhedral nanoclusters $\left(\mathrm{H}_{2} \mathrm{O}\right)_{\mathrm{n}}$, where $\mathrm{n}=3-20$ are carried out. Based on this data the main structural mathematical models describing water structure (quasi-crystalline, continuous, fractal, fractal-clathrate) have been examined and some important physical characteristics were obtained.
\end{abstract}

Keywords: hydrogen bond, water, structure, clusters, IR-spectroscopy, NES, DNES.

\section{Introduction}

Water with its anomalous physical and chemical properties outranks all other natural substances on the Earth. The ancient philosophers considered water as the most important component of the matter. It performs a vital role in numerous biochemical and metabolic processes occurring in cells with participation of water, being a universal polar solvent for hydrophilic molecules having an affinity for water. Hydroxyl groups (-OH) in $\mathrm{H}_{2} \mathrm{O}$ molecule, are polar and therefore hydrophilic. Moreover water act as a reagent for a big number of chemical reactions (hydrolysis, oxidation-reduction reactions). In chemical processes water due to its high ionizing ability possesses strong amphoteric properties, and can act both as an acid and a base in reactions of chemical exchange.

Modern science has confirmed the role of water as a universal life sustaining component, which defines the structure and properties of inorganic and organic objects, consisted from water.. The recent development of molecular and structural-chemical concepts has enabled to clarify an explanation of ability of water molecules to form the short-lived hydrogen bonds with neighboring molecules and many other chemical substances to bond them into intermolecular associates. It has also become clear the role of bounded water in forming hydrated substances and their physicochemical conduct in aqueous solutions.

The great scientific and practical interest have the studies of a variety of specific supramolecular structures - cyclic water clusters described by general formula $\left(\mathrm{H}_{2} \mathrm{O}\right)_{\mathrm{n}}$, which may be calculated and studied with the help of modern numerical computing methods. The clusters are also important for studying the structure of water and hydration phenomena at molecular level since they form the basic building blocks of the hydrated substances. This paper deals with the mathematical modeling of the water structure and water associates.

\section{Nature of Hydrogen Bond in Liquids and Crystals}

The peculiarities of chemical structure of $\mathrm{H}_{2} \mathrm{O}$ molecule and weak bonds caused by electrostatic forces and donoracceptor interaction between hydrogen and oxygen atoms in $\mathrm{H}_{2} \mathrm{O}$ molecules create favorable conditions for formation of directed intermolecular hydrogen bonds $(\mathrm{O}-\mathrm{H} \ldots \mathrm{O})$ with neighboring $\mathrm{H}_{2} \mathrm{O}$ molecules, binding them into complex intermolecular associates which composition represented by general formula $\left(\mathrm{H}_{2} \mathrm{O}\right)_{n}$, where $\mathrm{n}$ can vary from 3 to 50 (Keutsch \& Saykally, 2011). The hydrogen bond - a form of association between the electronegative $\mathrm{O}$-atom and a $\mathrm{H}$-atom, covalently bound to another electronegative O-atom, is of vital importance in the chemistry of intermolecular interactions, based on weak electrostatic forces and donor-acceptor interactions with charge-transfer (Pauling, 1960). It results from interaction between electron-deficient $\mathrm{H}$-atom of one $\mathrm{H}_{2} \mathrm{O}$ molecule (hydrogen donor) and unshared electron pair of an electronegative $\mathrm{O}$-atom (hydrogen acceptor) on the neighboring $\mathrm{H}_{2} \mathrm{O}$ molecule; the structure of hydrogen bonding, therefore may be defined as $\mathrm{O} \ldots \cdot \mathrm{H}^{\delta+}-\mathrm{O}^{\delta-}$. As the result, the electron of the $\mathrm{H}$-atom due to its relatively weak bond with the proton easily shifts to the electronegative $\mathrm{O}$-atom. The $\mathrm{O}$-atom with increased electron density becomes partly negatively charged $-\delta^{-}$, while the $\mathrm{H}$-atom on the opposite side of the molecule becomes positively charged $-\delta^{+}$that leads to the polarization of $\mathrm{O}^{\delta-}-\mathrm{H}^{\delta+}$ covalent bond. In this process the proton becomes almost bared, and due to the electrostatic attraction forces are provided good conditions for convergence of $\mathrm{O} \ldots \mathrm{O}$ or $\mathrm{O} \ldots \mathrm{H}$ atoms, leading to the chemical exchange of a proton in the reaction $\mathrm{O}-\mathrm{H} . . . \mathrm{O} \leftrightarrow \mathrm{O} \ldots \mathrm{H}-\mathrm{O}$. Although this interaction is essentially compensated by mutual repulsion of the molecules' nuclei and electrons, the effect of the electrostatic forces and donor-acceptor interactions for $\mathrm{H}_{2} \mathrm{O}$ molecule compiles 5-10 kcal per 1 mole of substance. It is explained by negligible small atomic radius of hydrogen 
and shortage of inner electron shells, which enables the neighboring $\mathrm{H}_{2} \mathrm{O}$ molecule to approach the hydrogen atom of another molecule at very close distance without experiencing any strong electrostatic repulsion.

The $\mathrm{H}_{2} \mathrm{O}$ molecule has, therefore, four sites of hydrogen bonding - two uncompensated positive charges at hydrogen atoms and two negative charges at the oxygen atom. Their mutual disposition is characterized by direction from the centre of regular tetrahedron (nucleus of oxygen atom) towards its vertexes. This allows to one $\mathrm{H}_{2} \mathrm{O}$ molecule in condensed state to form up to 4 classical hydrogen bonds, two of which are donor bonds and the other two - acceptor ones (taking into consideration bifurkate ("two-forked") hydrogen bond - 5) (Pasichnyk et al., 2008).

A hydrogen bond according to Bernal-Fowler rules (Bernal \& Fowler, 1933) is characterized by the following parameters:

a) an oxygen atom of each $\mathrm{H}_{2} \mathrm{O}$ molecule is bound with four neighboring hydrogen atoms: by covalent bonding with two own hydrogen atoms, and by hydrogen bonding - with two neighboring hydrogen atoms (as in the crystalline structure of ice); each hydrogen atom in its turn is bound with oxygen atom of neighbour $\mathrm{H}_{2} \mathrm{O}$ molecule. b) on the line of oxygen atom - there can be disposed only one proton $\mathrm{H}^{+}$;

c) the proton, which takes part in hydrogen bonding situated between two oxygen atoms, therefore has two equilibrium positions: it can be located near its oxygen atom at approximate distance of $1 \AA$, and near the neighboring oxygen atom at the distance of $1.7 \AA$ as well, hence both a usual dimer $\mathrm{HO}-\mathrm{H}_{\text {... }} \mathrm{OH}_{2}$ and an ion pair $\mathrm{HO} \ldots \mathrm{H}-\mathrm{OH}_{2}$ may be formed during hydrogen bonding, i.e. the hydrogen bond is part electrostatic $(\sim 90 \%)$ and part $(\sim 10 \%)$ covalent (Isaacs et al., 2000). The state of "a proton near the neighboring oxygen" is typical for the interphase boundary, i.e. near water-solid body or water-gas surfaces.

d) the hydrogen bonding of a triad $\mathrm{O}-\mathrm{H}$...O possess direction of the shorter $\mathrm{O}-\mathrm{H}(\rightarrow)$ covalent bond; the donor hydrogen bond tends to point directly at the acceptor electron pair (this direction means that the hydrogen atom being donated to the oxygen atom acceptor on another $\mathrm{H}_{2} \mathrm{O}$ molecule).

The most remarkable peculiarity of hydrogen bond consists in its relatively low strength; it is 5-10 times weaker than chemical covalent bond (Pimentel \& McClellan, 1960). In respect of energy hydrogen bond has an intermediate position between covalent bonds and intermolecular van der Waals forces, based on dipole-dipole interactions, holding the neutral molecules together in gasses or liquefied or solidified gasses. Hydrogen bonding produces interatomic distances shorter than the sum of van der Waals radii, and usually involves a limited number of interaction partners. These characteristics become more substantial when acceptors bind H-atoms from more electronegative donors. Hydrogen bonds hold $\mathrm{H}_{2} \mathrm{O}$ molecules on $15 \%$ closer than if water was a simple liquid with van der Waals interactions. The hydrogen bond energy compiles $5-10 \mathrm{kcal} / \mathrm{mole}$, while the energy of $\mathrm{O}-\mathrm{H}$ covalent bonds in $\mathrm{H}_{2} \mathrm{O}$ molecule $-109 \mathrm{kcal} /$ mole (Arunan et al., 2011). The values of the average energy $\left(\Delta \mathrm{E}_{\mathrm{H} \ldots \mathrm{O}}\right)$ of hydrogen $\mathrm{H}$... O-bonds between $\mathrm{H}_{2} \mathrm{O}$ molecules make up $0.1067 \pm 0.0011 \mathrm{eV}$ (Antonov \& Galabova, 1992). With fluctuations of water temperature the average energy of hydrogen H...O-bonds in of water molecule associates changes. That is why hydrogen bonds in liquid state are relatively weak and unstable: it is thought that they can easily form and disappear as the result of temperature fluctuations (Ignatov \& Mosin, 2013a).

Another key feature of hydrogen bond consists in its cooperativity coupling. Hydrogen bonding leads to the formation of the next hydrogen bond and redistribution of electrons, which in its turn promotes the formation of the following hydrogen bond, which length increasing with distance. Cooperative hydrogen bonding increases the $\mathrm{O}-\mathrm{H}$ bond length, at the same time causing a reduction in the H... O and O...O distances (Goryainov, 2012). The protons held by individual $\mathrm{H}_{2} \mathrm{O}$ molecules may switch partners in an ordered manner within hydrogen networks (Bartha et al., 2003). As the result, aqueous solutions may undergo autoprotolysis, i.e. the $\mathrm{H}^{+}$proton is released from $\mathrm{H}_{2} \mathrm{O}$ molecule and then transferred and accepted by the neighboring $\mathrm{H}_{2} \mathrm{O}$ molecule resulting in formation of hydronium ions as $\mathrm{H}_{3} \mathrm{O}^{+}, \mathrm{H}_{5} \mathrm{O}_{2}{ }^{+}, \mathrm{H}_{7} \mathrm{O}_{3}{ }^{+}, \mathrm{H}_{9} \mathrm{O}_{4}{ }^{+}$, etc. This leads to the fact, that water should be considered as associated liquid composed from a set of individual $\mathrm{H}_{2} \mathrm{O}$ molecules, linked together by hydrogen bonds and weak intermolecular van der Waals forces (Liu et al., 1996). The simplest example of such associate can be a dimmer of water:

$$
\left(\mathrm{H}_{2} \mathrm{O}\right)_{2}=\mathrm{H}_{2} \mathrm{O} \cdots \mathrm{HOH}
$$

The energy of the hydrogen bonding in the water dimer is $0.2 \mathrm{eV}(\sim 5 \mathrm{kcal} / \mathrm{mol})$, which is larger than the energy of thermal motion of the molecules at the temperature of $300 \mathrm{~K}$. Hydrogen bonds are easily disintegrated and re-formed through an interval of time, which makes water structure quite unstable and changeable (George, 1997). This process leads to structural inhomogeneity of water characterizing it as an associated heterogeneous two-phase liquid with short-range ordering, i.e. with regularity in mutual positioning of atoms and molecules, which reoccurs only at distances comparable to distances between initial atoms, i.e. the first $\mathrm{H}_{2} \mathrm{O}$ layer. As it is known, a liquid in contrast to a solid body, is a dynamic system: its atoms, ions or molecules, keeping short-range order in mutual disposition, participate in thermal motion, the character of which is much more complicated than that of crystals. For example $\mathrm{H}_{2} \mathrm{O}$ molecules in liquid state under normal conditions $\left(1 \mathrm{~atm}, 22{ }^{\circ} \mathrm{C}\right)$ are quiet mobile and can oscillate around their rotation axes, as well as to perform the random and directed shifts. This enabled for some individual molecules due to cooperative interactions to "jump up" from one place to another in an elementary 
volume of water. Random motion of molecules in liquids causes continuous changes in the distances between them. The statistical character of ordered arrangement of molecules in liquids results in fluctuations - continuously occurring deviations not only from average density, but from average orientation as well, because molecules in liquids are capable to form groups, in which a particular orientation prevails. Thus, the smaller these deviations are, the more frequently they occur in liquids.

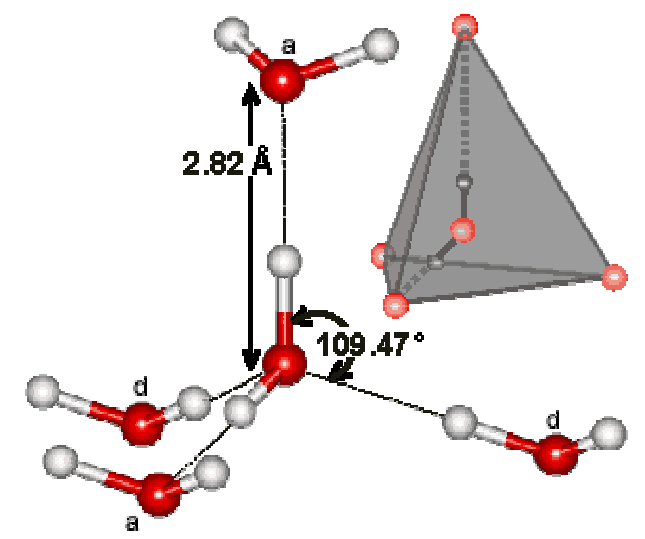

Figure 1: The formation of a hydrogen bond between the four molecules of $\mathrm{H}_{2} \mathrm{O}$ (red spheres indicate the central atoms of oxygen, white balls - hydrogen atoms). It is shown the value of the angle between the covalent $\mathrm{H}-\mathrm{O}-\mathrm{H}$ bond in $\mathrm{H}_{2} \mathrm{O}$ molecule and the length of the hydrogen bond

The further important feature is that the hydrogen bonds are spatially oriented. As each $\mathrm{H}_{2} \mathrm{O}$ molecule has four sites of hydrogen bond formation (two non-shared electron pairs at an oxygen atom and two uncompensated positive charges at a hydrogen atom), one $\mathrm{H}_{2} \mathrm{O}$ molecule in a condensed state is capable to form hydrogen bonds with four $\mathrm{H}_{2} \mathrm{O}$ molecules (two donor and two acceptor) (Figure 1), which results in forming a tetrahedron crystal structure clearly observed in ice crystals.

At present time 14 crystalline modifications of ice are known, each of them has its own structure and a character of disposition of hydrogen atoms (Table 1). Crystals of all ice modifications are made up from $\mathrm{H}_{2} \mathrm{O}$ molecules, linked by hydrogen bonds into a 3D carcass, consisting of individual tetrahedrons, formed by four $\mathrm{H}_{2} \mathrm{O}$ molecules (Fig 2). In the crystalline structure of natural ice $\mathrm{I}_{\mathrm{h}}$ hydrogen bonds are oriented towards the tetrahedron apexes at strictly defined angles equal to $109^{\circ} 5$ (in liquid water this angle is $104^{0} 5$ ) (Mosin \& Ignatov, 2013a). In ice structures $I_{c}$, VII and VIII this tetrahedron is nearly the same as a regular 4 triangular tetrahedron. In ice structures II, III, V and VI the tetrahedrons are noticeably distorted. In ice structures VI, VII and VIII two intercrossing systems of hydrogen bonds are distinguished. In the centre of the tetrahedron is located an oxygen atom, at each of the two vertices - H-atom, which electron take part in formation of covalent bond with an electron pair of $\mathrm{O}$-atom. The rest two vertices of the tetrahedron are occupied by two pairs of non -shared electrons of Oatom not participating in formation of molecular bonds.

Table: Ice Crystal modifications and their physical characteristics

\begin{tabular}{|l|l|l|l|}
\hline Modification & Crystal structure & Hydrogen bond lengths, $\AA$ & Angles H-O-H in tetragonals, ${ }^{0}$ \\
\hline $\mathrm{I}_{\mathrm{h}}$ & Hexagonal & 2.76 & 109.5 \\
\hline $\mathrm{I}_{\mathrm{c}}$ & Cubic & 2.76 & 109.5 \\
\hline II & Trigonal & $2.75-2.84$ & $80-128$ \\
\hline III & Tetragonal & $2.76-2.8$ & $87-141$ \\
\hline IV & Rhombic & $2.78-2.88$ & $70.1-109$ \\
\hline V & Monoclinic & $2.76-2,87$ & $84-135$ \\
\hline VI & Tetragonal & $2.79-2.82$ & $76-128$ \\
\hline VII & Cubic & 2.86 & 109.5 \\
\hline VIII & Cubic & 2.86 & 109.5 \\
\hline IX & Tetragonal & $2.76-2.8$ & $87-141$ \\
\hline X & Cubic & 2.78 & 109.5 \\
\hline XI & Hexagonal & 4.50 & 90.0 \\
\hline XII & Tetragonal & 4.01 & 90.0 \\
\hline XIII & Monoclinic & 7.47 & $90-109.7$ \\
\hline XIV & Rhombic & 4.08 & 90.0 \\
\hline
\end{tabular}

Notes: $\mathrm{I}_{\mathrm{h}}$ - natural hexagonal ice; $\mathrm{I}_{\mathrm{c}}-$ cubic ice. 
Table 2: Physical properties of ice $\mathrm{I}_{\mathrm{h}}$

\begin{tabular}{|c|c|c|}
\hline Property & Value & Note \\
\hline Heat capacity, cal $/\left(\mathrm{g}^{0} \mathrm{C}\right)$ & $0.51\left(0{ }^{0} \mathrm{C}\right)$ & $\begin{array}{l}\text { Significantly decreases with } \\
\text { decreasing temperature }\end{array}$ \\
\hline Heat of melting, cal/g & 79.69 & - \\
\hline Heat of vaporization, cal/g & 677 & - \\
\hline The coefficient of thermal expansion, $1 /{ }^{0} \mathrm{C}$ & $9.1 \cdot 10^{-5}\left(0^{0} \mathrm{C}\right)$ & Polycrystalline ice \\
\hline Thermal conductivity, $\mathrm{cal} /\left(\mathrm{cm} \cdot \mathrm{sec} \cdot{ }^{0} \mathrm{C}\right)$ & $4.99 \cdot 10^{-3}$ & Polycrystalline ice \\
\hline Refractive index & $1.309\left(-3^{0} \mathrm{C}\right)$ & Polycrystalline ice \\
\hline Specific electrical conductivity, $\mathrm{Ohm}^{-1} \cdot \mathrm{cm}^{-1}$ & $10^{-9}\left(0^{0} \mathrm{C}\right)$ & $\begin{array}{l}\text { The apparent activation energy of } 11 \\
\mathrm{kcal} / \mathrm{mol}\end{array}$ \\
\hline Surface conductivity, $\mathrm{Ohm}^{-1}$ & $10^{-10}\left(-11^{0} \mathrm{C}\right)$ & $\begin{array}{l}\text { The apparent activation energy of } 32 \\
\mathrm{kcal} / \mathrm{mol}\end{array}$ \\
\hline Modulus of elasticity Young's, $1 \mathrm{~g} \cdot \mathrm{cm} / \mathrm{s}^{2} / \mathrm{cm}^{2}$ & $9 \cdot 10^{10}\left(-5^{0} \mathrm{C}\right)$ & Polycrystalline ice \\
\hline \multicolumn{3}{|l|}{ Resistance, $\mathrm{MH} / \mathrm{M}^{2}$ : } \\
\hline crushing & 2.5 & Polycrystalline ice \\
\hline rupture & 1.11 & Polycrystalline ice \\
\hline shear & 0.57 & Polycrystalline ice \\
\hline Dynamic viscosity, Poise & $10^{14}$ & Polycrystalline ice \\
\hline $\begin{array}{l}\text { The activation energy during deformation and } \\
\text { mechanical relaxation } \mathrm{kcal} / \mathrm{mol}\end{array}$ & $11.44-21.3$ & $\begin{array}{l}\text { Increases linearly at } 0.0361 \\
\mathrm{kcal} /\left(\mathrm{mol}^{.0} \mathrm{C}\right) \text { from } 0 \text { to } 273.16 \mathrm{~K}\end{array}$ \\
\hline
\end{tabular}

Notes: $1 \mathrm{cal} /\left(\mathrm{g} \cdot{ }^{0} \mathrm{C}\right)=4.186 \mathrm{~kJ} /(\mathrm{kg} \cdot \mathrm{K}) ; 1 \mathrm{Ohm}^{-1} \cdot \mathrm{cm}^{-1}=100 \mathrm{Sim} / \mathrm{m} ; 1 \mathrm{dyn}=10^{-5} \mathrm{~N} ; 1 \mathrm{~N}=1 \mathrm{~kg} \cdot \mathrm{m} / \mathrm{s}^{2} ; 1 \mathrm{dyn} / \mathrm{cm}=10^{-7}$ $\mathrm{H} / \mathrm{M} ; 1 \mathrm{cal} /\left(\mathrm{cm} \cdot \mathrm{s}^{0} \mathrm{C}\right)=418.68 \mathrm{~W} /(\mathrm{M} \cdot \mathrm{K}) ; 1$ Poise $=\mathrm{g} / \mathrm{cm} \cdot \mathrm{s}=10^{-1} \mathrm{~N} \cdot \mathrm{s} / \mathrm{m}^{2}$.

High pressure ice of trigonal II and tetragonal III modifications is formed by hollow combs, formed by the hexagonal corrugated elements shifted from each other by $1 / 3$ (Fig. 2 b,c ). These ice structures are stabilized in the presence of the noble gases as helium and argon. In the monoclinic structure of ice $\mathrm{V}$ the angles between the neighboring $\mathrm{O}$-atoms are varied from $86^{\circ}$ to $132^{\circ}$, which is very different from the valence angle in the $\mathrm{H}_{2} \mathrm{O}$ molecule makes up $105^{\circ} 47^{\prime}$. Ice of VI tetragonal modification consists of two inserted into each other scaffolds, between which there are no H-bonds, resulting in a body-centered crystal lattice (Fig. $2 \mathrm{e}$ ). The basis of the structure of ice VI constitutes the hexamers - blocks of six $\mathrm{H}_{2} \mathrm{O}$ molecules. Their configuration is exactly the same as the structure of a stable cluster of water, which gave computer calculations. A similar structure with frames of ice I, inserted into each other, have ice of cubic modification of VII and VIII, which are low temperature ordered forms of ice VII. Upon the pressure increasing the distance between O-atoms in the crystal lattice of ice VII and ice VIII will decreases, as a result is formed the ice structure $\mathrm{X}$, in which $\mathrm{O}$-atoms are arranged in a regular grid with arranged protons.

Ice XI is formed by deep freezing of ice $\mathrm{I}_{\mathrm{h}}$ with addition of alkali below $72 \mathrm{~K}$ at normal pressure. Under these conditions, the hydroxyl defects of the crystal are formed, allowing to the growing ice crystals change their structure. Ice XI has a rhombic crystal lattice with an ordered arrangement of protons and is formed simultaneously in many centers of crystallization around the hydroxyl crystal defects.

Among the ice there and metastable forms of IV and XII, which lifetimes are seconds (Fig. 2 d,f). For obtaining the structures of the metastable ice, the ice $\mathrm{I}_{\mathrm{h}}$ is to be compressed to a pressure of $1.8 \mathrm{GPa}$ at a temperature of liquid $\mathrm{N}_{2}$. These ice structures are formed much easier and especially stable if supercooled heavy water is subjected to pressure. Another modification of the metastable ice IX is formed by supercooling of ice III and, therefore, is its low temperature form.

The last two modifications of ice - the monoclinic XIII and rhombic XIV configuration were discovered by scientists from Oxford (UK) in 2006. On Earth, such modifications of ice cannot be formed, but they can exist on the cooled frozen planets and comets. The calculation of density and the heat flows from the surface of the moons of Jupiter and Saturn suggests that Ganymede and Callisto has to be the ice shells, in which alternate ice I, III, V and VI. At the Titan's the ice does not form a crust shell, but the mantle, the inner layer of which consists of ice VI and other high-pressure ice modifications and clathrate hydrates, on the top of which is located hexagonal ice $\mathrm{I}_{\mathrm{h}}$.

In ice $\mathrm{I}_{\mathrm{h}}$ the carcasses of hydrogen bonds allocate $\mathrm{H}_{2} \mathrm{O}$ molecules in form of a spatial hexagon network with internal hollow hexagonal channels. In the nodes of this network O-atoms are orderly organized (crystalline state), forming regular hexagons, while $\mathrm{H}$-atoms have various positions along the bonds (amorphous state). When ice melts, its network structure is destroyed: $\mathrm{H}_{2} \mathrm{O}$ molecules begin to fall down into the network hollows, resulting in a denser structure of the liquid - this explains why water is heavier than ice. The hydrogen bonding explains other anomalies of water (anomality of temperature, pressure, density, viscosity, fluidity etc. According to theoretical calculations, at the melting of the ice breaks about $15 \%$ of all hydrogen bonds (Mosin \& Ignatov, 2011); 
by further heating up to $+40{ }^{\circ} \mathrm{C}$ breaks down about half of hydrogen bonds in water associates. In the water vapor hydrogen bonds are absent. The physical properties of ice $\mathrm{I}_{\mathrm{h}}$ are shown in Table 2.

The main difference between the structure of ice and water is more diffuse arrangement of the atoms in the lattice and disturbance of long-range order. Thermal oscillations (fluctuations) lead to bending and breaking of hydrogen bonds. Those out of the equilibrium positions $\mathrm{H}_{2} \mathrm{O}$ molecules fall into the adjacent structural voids and for a time held up there, as cavities correspond to the relative minimum of potential energy. This leads to an increase in the coordination number, and the formation of lattice defects. The coordination number (the number of nearest neighbors) varies from 4.4 at $+1.5{ }^{\circ} \mathrm{C}$ to 4.9 at $+80{ }^{\circ} \mathrm{C}$.

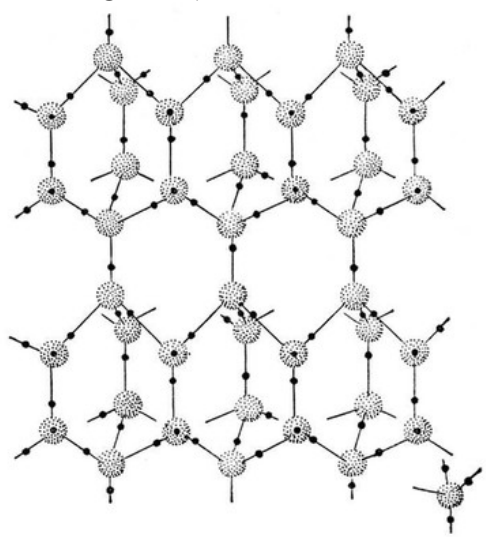

a)

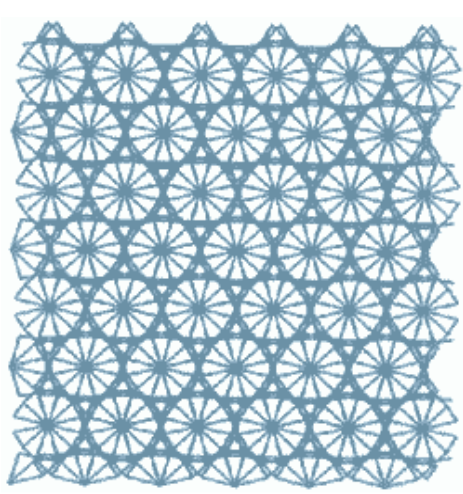

d)

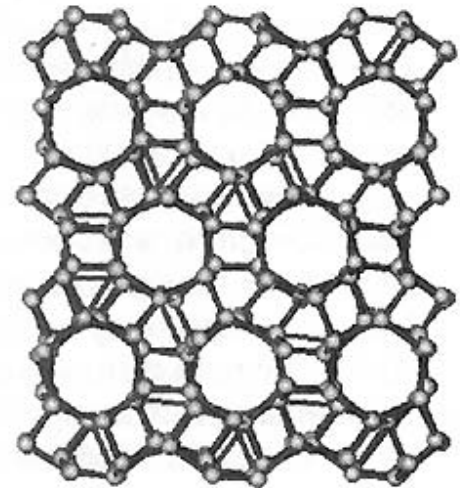

b)

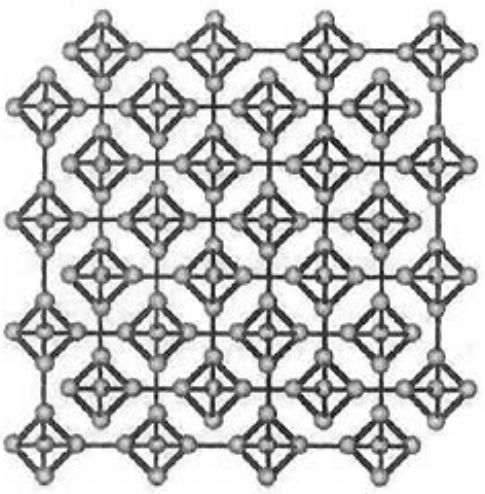

e)

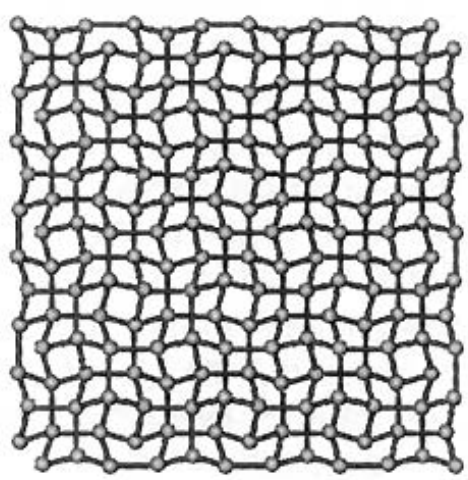

c)

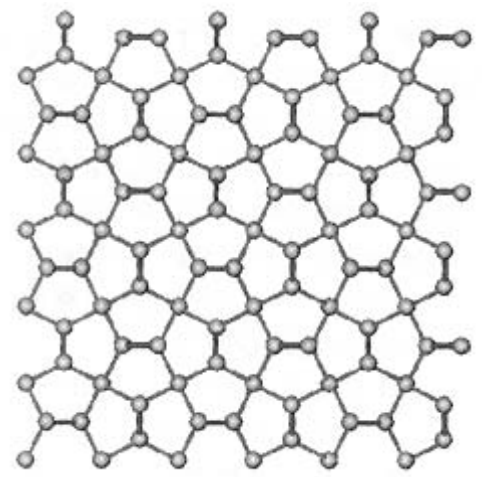

f)

Figure 2: Ice crystalline modifications: $a$ ) - natural hexagonal ice $\mathrm{I}_{\mathrm{h}} ; b$ ) - ice of II configuration; $c$ ) - ice of III configuration; $d$ ) - ice of IV configuration; $e$ ) - ice of VI configuration; $f$ ) - ice of XII configuration.
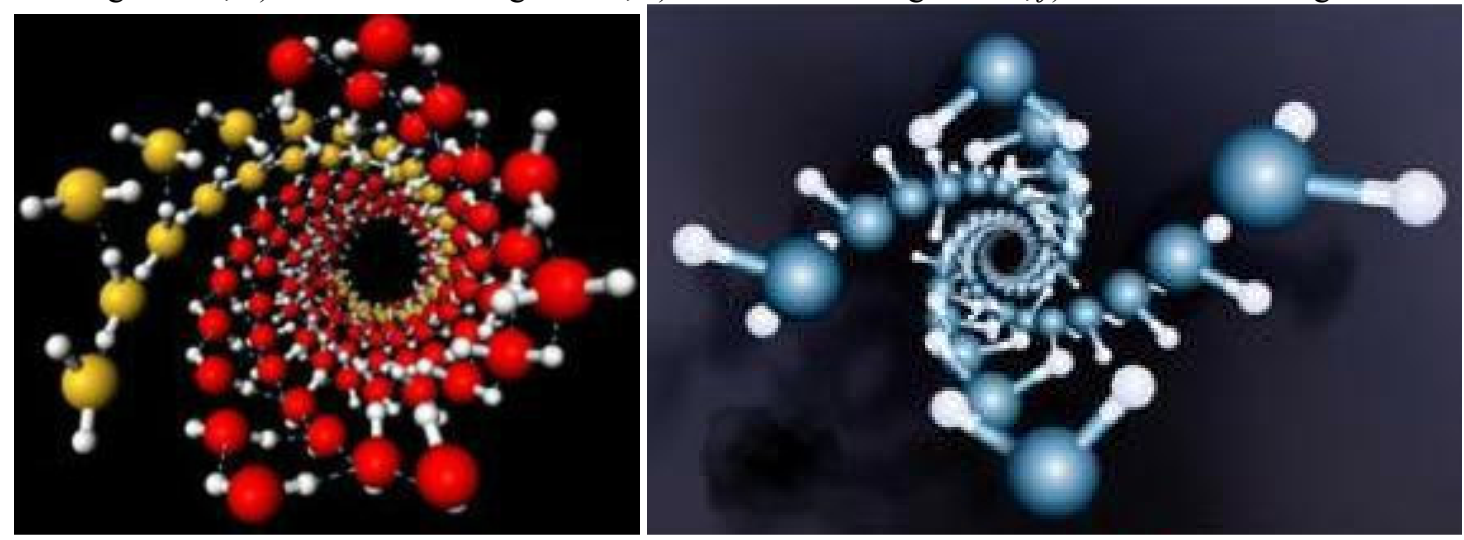

b)

Figure 3: Structures of water crystals in carbon nanotubes according to computer simulations (Bai et al., 2006) (diameter of nanotubes 1.35-1.90 nm; preassure 10-40000 atm; temperature $-23^{\circ} \mathrm{C}$ ): $a$ ) - a general view of the crystal structure of water in nanotubes, $b$ ) - the inner wall of the structure of water. 


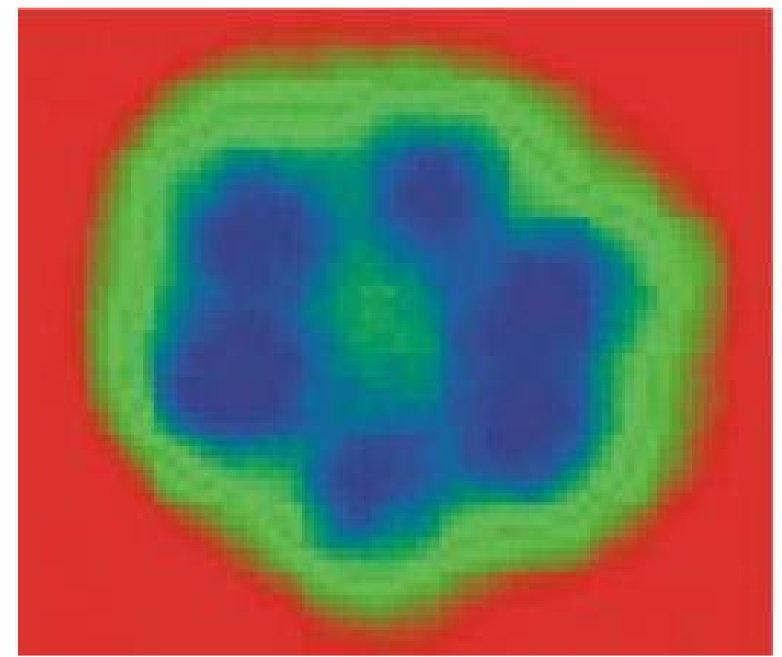

Figure 4: Image of hexamer nanocrystal of ice water (average size $\sim 1 \mathrm{~nm}$ ) by a scanning tunneling microscope after freezing water to $17 \mathrm{~K}$ on the hydrophobic metallic plates of $\mathrm{Cu}$ and $\mathrm{Ag}$ (Michaelides \& Morgenstern, 2007).

Reports about evidence of existence of crystal-like structures in water have become more frequent in scientific literature nowadays (Michaelides \& Morgenstern, 2007). As computer modeling showed, $\mathrm{H}_{2} \mathrm{O}$ molecules being placed in carbon nanotubes under high pressure and low temperatures formed crystalline nanostructures like DNA double helix (Bai et al., 2006). In modeling experiment water got frozen inside carbon nanotubes with diameter $1.35-1.90 \mathrm{~nm}$ with pressure $10-40000 \mathrm{~atm}$ and temperature $-23^{\circ} \mathrm{C}$. Hydrogen bonds in an ice crystal got distorted leading to the formation of a double-walled helix. The inner wall of this structure represents a four-fold twisted helix, while the outer consists of four double helixes, resembling a helix of DNA molecule (Figure 3). While being frozen at $17 \mathrm{~K}$ on hydrophobic surfaces of $\mathrm{Cu}, \mathrm{Ag}$ and their salts, water became crystallized into twodimensional ice hexamer nanocrystal, consisting of six attached together $\mathrm{H}_{2} \mathrm{O}$ molecules (Figure 4).

\section{Structural Mathematical Models of Water}

There are several groups of models, describing structure of liquids - microcrystalline, quasicrystalline, continious, fractal and fractal-clathrate models. The microcrystalline model of J. Bernal and P. Fowler suggests that water is a nonequilibrium 2-phase liquid containing groups of oriented molecules - microcrystals with several dozens or hundreds of molecules (Bernal \& Fowler, 1933; Timothy \& Zwier, 2004). Within each microcrystal in liquid a solid body ordering (long-range order) is strictly kept. As water is denser than ice, it is assumed that its molecules are allocated in a different way than in ice: like the atoms of silicon in mineral tridymite or in its more solid modification of quarz. The intermittent increase in water density from 0 to $3.98^{\circ} \mathrm{C}$ and other anomalous properties of water was explained by the existence of tridymite component at low temperatures (Pople, 1951).

Quasicrystalline model by analogy with a quasicrystal, e.g. a structure that is ordered but not periodic (Nemukhin, 1996), suggests that relative disposition of particles in liquids is nearly the same as in crystals; deviation from regularity increases with the distance from the initial $\mathrm{H}_{2} \mathrm{O}$ molecule; far apart at longer distances there is no regularity in the disposition of $\mathrm{H}_{2} \mathrm{O}$ molecules. Each $\mathrm{H}_{2} \mathrm{O}$ molecule is surrounded by the four neighbouring ones, which are arranged around it in quite the same way, as they are in an ice crystal. However, in the second layer there appear deviations from regularity rapidly increasing with distance from the initial $\mathrm{H}_{2} \mathrm{O}$ molecule. Studies of X-ray scattering in liquids consisting of polyatomic molecules, revealed not only some regular arrangement of $\mathrm{H}_{2} \mathrm{O}$ molecules, but consistent pattern in mutual orientation of the molecules (Petkov et al., 2012). This orientation becomes even more expressed for the polar molecules because of the hydrogen bonding effect.

Kinetic theory of liquids proposed by Y.I. Frenkel, also called a "jump-wait" model, explains the structural properties of liquids by peculiarities of thermal motion of their molecules (Frenkel, 1975). The thermal motion of $\mathrm{H}_{2} \mathrm{O}$ molecules is characterized by two parameters: a period of oscillation of $\mathrm{H}_{2} \mathrm{O}$ molecule around an equilibrium position and a period of "settled life", i.e. period of oscillation around one particular equilibrium position. Average time of "settled life" of a $\mathrm{H}_{2} \mathrm{O}$ molecule, within which $\mathrm{H}_{2} \mathrm{O}$ molecules keep unchanged equilibrium orientation is called relaxation time $\tau$ :

$$
\tau=\tau_{0} \times \mathrm{e}^{\mathrm{W} / \mathrm{RT}},
$$

where $\tau_{0}$ is an average period of oscillations of a $\mathrm{H}_{2} \mathrm{O}$ molecule around an equilibrium position (sec), W - a value of potential energy barrier, separating two neighboring equilibrium positions from each other $(\mathrm{J}), \mathrm{R}-$ Boltzmann constant $(\mathrm{J} / \mathrm{K}), \mathrm{T}-$ absolute temperature $(\mathrm{K})$.

According to calculations the relaxation time at room temperature makes up $\sim 4.5 \cdot 10^{-12} \mathrm{sec}$, while the 
period of one oscillation of $\mathrm{H}_{2} \mathrm{O}$ molecules $-10^{-12}-10^{-13} \mathrm{sec}$. That is why each $\mathrm{H}_{2} \mathrm{O}$ molecule performs approximately 100 oscillations relative to the same equilibrium position before changing its place. Due to thermal fluctuations one $\mathrm{H}_{2} \mathrm{O}$ molecule within its "settled life" period of time oscillates around an equilibrium position, after then jumps up to new location and it continues to fluctuate up to the next jump. Through these abrupt movements of molecules in liquids occurs diffusion, which, in contrast to the continuous diffusion in gases, called diffusion jump. With increase in temperature the period of "settled life" of $\mathrm{H}_{2} \mathrm{O}$ molecules in a temporary state of equilibrium is reduced that brings the structure of water closer to a gas, in which translational and rotational motions of $\mathrm{H}_{2} \mathrm{O}$ molecules prevail. Theoretical studies show that, along with the fluctuation of molecules surrounded by his neighbors and activation jumps in liquids occur flowing movement of molecules along with their immediate environment. In other words, being in oscillating state, the molecules in the liquid displaced each time by a certain distance (less than the interatomic distance), causing continuous diffusion. It is believed that in the liquefied inert gases and metals dominates continuous diffusion, while for associated liquids as water is more likely the jump diffusion mechanism. The thermal motion of $\mathrm{H}_{2} \mathrm{O}$ molecules leads to continuous changes in distances between them, which cause fluctuations - continual deviations not only from the average density, but from the average orientation of the molecules as well, because $\mathrm{H}_{2} \mathrm{O}$ molecules can form groups in which a certain orientation predominates. An attempt to change the water volume (even by small quantity) triggers the process of deformation of hydrogen bonds that fact may explain low water compressibility. Ice melting also causes weakening and deformation of hydrogen bonds, which makes water denser than ice. At the temperature $3.98^{\circ} \mathrm{C}$ water acquires anomalous state, in which the quasicrystalline phase is maximally densified by filling up of ice carcass hollows with $\mathrm{H}_{2} \mathrm{O}$ molecules. Further increase in temperature and energy of thermal motion of $\mathrm{H}_{2} \mathrm{O}$ molecules leads to the gradual disintegration of associated water structures and to the partial rupture of hydrogen bonds with essential reduce of the "settled life" of each $\mathrm{H}_{2} \mathrm{O}$ molecule in water associates.

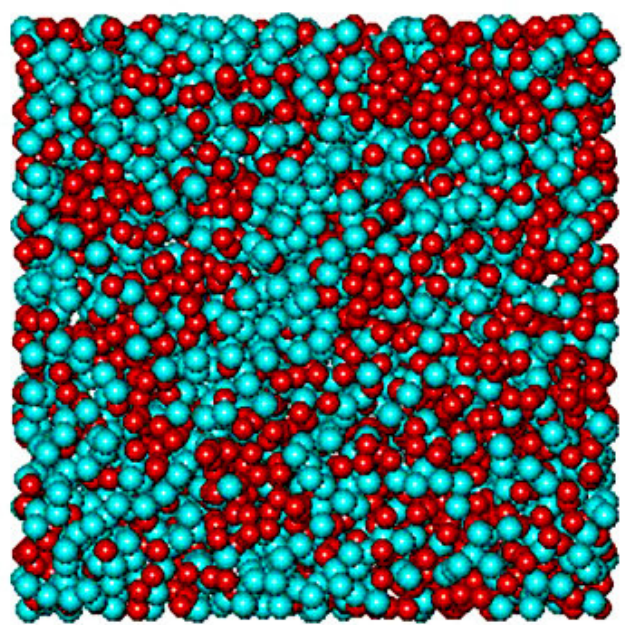

Figure 5: The model composing of 3456 water molecules at a temperature of $297 \mathrm{~K}$. Red balls $-\mathrm{H}_{2} \mathrm{O}$ molecules with the low values of the Voronoi polyhedra volume (less than $26.33 \AA$ ), i.e. molecules in areas with a higher local density. Blue - molecules with the large volumes of values (more than $34.1 \AA$ ). It was selected by $25 \%$ of the molecules of each kind. It is evident that the molecules of each kind have a tendency to associate with each other, showing the scale of existing structural inhomogeneities in the water. 


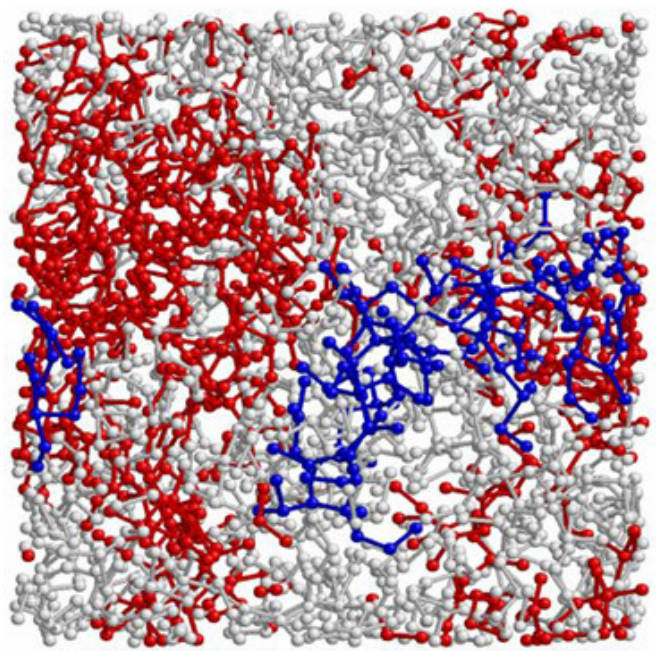

Figure 6: Coloring of hydrogen bonds according to their lifetimes. Small ball shows molecular centers, bound by bonds living longer than 19 ps. The largest cluster $\left(885\right.$ molecules $\left.\mathrm{H}_{2} \mathrm{O}\right)$ shows red. Blue shows a cluster of 154 molecules. The remaining, smaller clusters are shown in gray. The molecules in the clusters are tended to move in unison. The water model consisting of 3456 molecules $\mathrm{H}_{2} \mathrm{O}$ at a temperature of $262 \mathrm{~K}$ (supercooled water)

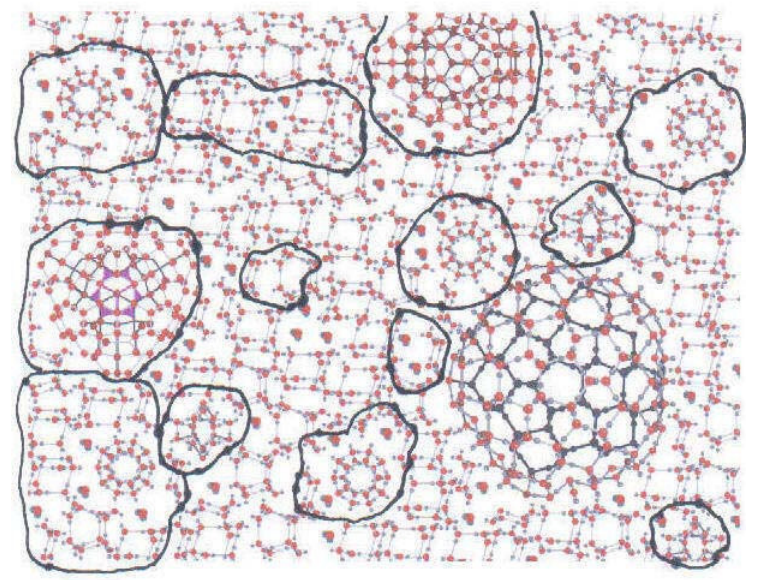

Figure 7: Schematic representation of the space-filling mixture molecules-elements that may exist in a certain proportion of small, 2-4 molecules $\mathrm{H}_{2} \mathrm{O}$, clusters and other larger molecules $\mathrm{H}_{2} \mathrm{O}$, up to the calculated $\mathrm{H}_{2} \mathrm{O}$ molecules composing from $280 \mathrm{H}_{2} \mathrm{O}$ molecules-elements. It underlines the key role of heterogeneity in the structure of water. Unfortunately, due to lack of data it is difficult to portray to scale spatial relationships between the molecules of both real and likely present clusters. The forces between the clusters are marked in black. They are much weaker than the forces inside the clusters, however these connections are not allocated (Roy R, 2004) The continuous and "fractal" models consider water as a complex dynamic system with a hydrogen network, forming the empty cavities and non-bonded $\mathrm{H}_{2} \mathrm{O}$ molecules distributed within the network (Figure 5-7). The structure is based upon dimensional carcasses of individual $\mathrm{H}_{2} \mathrm{O}$ molecules, joined together into a multi-molecular associate similar to a clathrate having a configuration of a regular polyhedron (Samoilov, 1963). Analogous structure has clathrate hydrates (gas clathrates) - crystalline water-based solids physically resembling ice, in which small non polar gas molecules are placed inside cavities of hydrogen bonded $\mathrm{H}_{2} \mathrm{O}$ molecules.

In $1957 \mathrm{~S}$. Frank and W. Wen proposed a model, postulating arbitrary formation of cyclic associates in water, which presumably had random groups of water associates - the "flickering clusters" with general formula $\left(\mathrm{H}_{2} \mathrm{O}\right)_{n}$, which are in a dynamic equilibrium with free $\mathrm{H}_{2} \mathrm{O}$ molecules (Henry et al., 1957). The hydrogen bonds between $\mathrm{H}_{2} \mathrm{O}$ molecules are in dynamic equilibrium; they are constantly broken and re-formed in new configurations within a certain time interval; these processes are occurred cooperatively within short-living associated groups of $\mathrm{H}_{2} \mathrm{O}$ molecules (clusters), which life spans are estimated from $10^{-10}$ to $10^{-11} \mathrm{sec}$.

Water associates evidently may have polymer structure, because hydrogen bond is on $10 \%$ partially covalent bond (Isaacs et al., 2000). In 1990 G.A. Domrachev and D.A. Selivanovsky formulated a model of $\mathrm{H}_{2} \mathrm{O}-$ polimers based on the existence of mechanochemical reactions of ionization and dissociation of water in aqueous solutions (Domrachev \& Selivanovsky, 1990). Water was thought as dynamically unstable quazi-polymer, composed of $\left(\mathrm{H}_{2} \mathrm{O}\right)_{n}$ blocks with partially covalent by $10 \%$ hydrogen bonds, permitting at least to $10 \%$ of $\mathrm{H}_{2} \mathrm{O}$ 
molecules to comby in a sufficiently long-lived polymer associates. Similarly with mechanochemical reactions in polymers, in case of mechanical impact on water, the energy absorbed by water required for splitting up the $\mathrm{H}-$ $\mathrm{OH}$ bond, concentrates in a micro-scale area of the liquid water structure.

The splitting up reaction of the $\mathrm{H}-\mathrm{OH}$ bond in water polymer associates is expressed by the following equation:

$$
\left(\mathrm{H}_{2} \mathrm{O}\right)_{n}\left(\mathrm{H}_{2} \mathrm{O} \ldots \mathrm{H}-\mid-\mathrm{OH}\right)\left(\mathrm{H}_{2} \mathrm{O}\right)_{m}+\mathrm{E}=\left(\mathrm{H}_{2} \mathrm{O}\right)_{n+1}(\mathrm{H})+(\mathrm{OH})\left(\mathrm{H}_{2} \mathrm{O}\right)_{m},
$$

where $\mathrm{E}$ - the energy of the $\mathrm{H}-\mathrm{OH}$ bond, $460 \mathrm{\kappa J} / \mathrm{mole}$; the dot denotes an unpaired electron.

Splitting up of the $\mathrm{H}-\mathrm{OH}$ bond is accompanied by formation of new disordered bonds between "fragments" of the initial molecules, leading to the formation of fluctuation areas with different density fluctuations that can be observed in aqueous solutions.

Another interesting physical phenomenon was discovered by A. Antonov in 2005 (Antonov, 2005). It was established experimentally that at evaporation of water droplet the contact angle $\theta$ decreases discretely to zero, whereas the diameter of the droplet changes insignificantly. By measuring this angle within a regular time intervals a functional dependence $\mathrm{f}(\theta)$ can be determined, which is designated by the spectrum of the water state. For practical purposes by registering the spectrum of water state it is possible to obtain information about the averaged energy of hydrogen bonds in an aqueous sample. For this purpose the model of W. Luck is used, which consider water as an associated liquid, consisted of $\mathrm{O}-\mathrm{H} . . . \mathrm{O}-\mathrm{H}$ groups (Luck et al., 1980). The major part of these groups is designated by the energy of hydrogen bonds $(-E)$, while the others are free $(E=0)$. The energy distribution function $\mathrm{f}(\mathrm{E})$ is measured in electron-volts $\left(\mathrm{eV}^{-1}\right)$ and may be varied under the influence of various external factors on water as temperature and pressure.

For calculation of the function $\mathrm{f}(\mathrm{E})$ experimental dependence between the water surface tension $(\theta)$ and the energy of hydrogen bonds $(\mathrm{E})$ is established:

$$
f(E)=\frac{14,33 f(\theta)}{\left[1-(1+b E)^{2}\right]^{2}}
$$

where $b=14.33 \mathrm{eV}^{-1}$

The energy of hydrogen bonds $(\mathrm{E})$ is measured in electron-volts $(\mathrm{eV})$ and is designated by the spectrum of energy distribution. The water spectrum characterized by a non-equilibrium process of water droplets evaporation, thus the term "non-equilibrium energy spectrum of water" (NES) is applied.

The difference $\Delta f(E)=f$ (samples of water) - $f$ (control sample of water) is called the "differential non-equilibrium energy spectrum of water" (DNES).

DNES is a measure of changes in the structure of water as a result of external influences. The cumulative effect of all other factors is the same for the control sample of water and the water sample, which is under the influence of this impact.

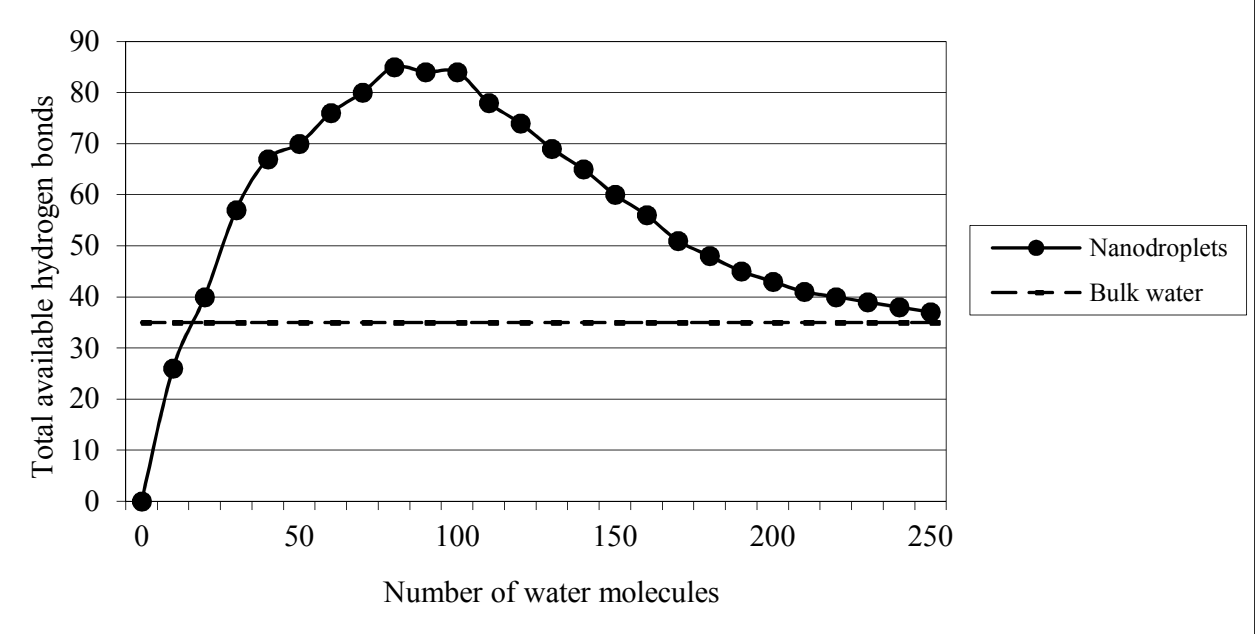

Figure 8: The total number of hydrogen bonds depending on the number of water molecules in clusters.

In 2005 R. Saykally (University of California, USA) calculated the possible number of hydrogen bonds and the stability of water clusters depending on the number of $\mathrm{H}_{2} \mathrm{O}$ molecules (Figure 8) (Saykally, 2005). It was also estimated the possible number of hydrogen bonds (100) depending on the number of $\mathrm{H}_{2} \mathrm{O}$ molecules (250) in clusters (Sykes, 2007).

O. Loboda and O.V. Goncharuk provided data about the existence of icosahedral water clusters consisting of $280 \mathrm{H}_{2} \mathrm{O}$ molecules with the average size up to $3 \mathrm{~nm}$ (Loboda \& Goncharuk, 2010). The ordering of water molecules into associates corresponds to a decrease in the entropy (randomness), or decrease in the overall Gibbs energy $(\mathrm{G}=\Delta \mathrm{H}-\mathrm{T} \Delta \mathrm{S})$. This means that the change in enthalpy $\Delta \mathrm{H}$ minus the change in entropy $\Delta \mathrm{S}$ (multiplied 
by the absolute temperature T) is a negative value. These results are consistent with our data on research of DNES spectrum of water on which it may make conclusion about the number of $\mathrm{H}_{2} \mathrm{O}$ molecules in water clusters. DNES spectrum of water has energy ranges from -0.08 to $-0.14 \mathrm{eV}$ (Figure 9). The spectral range lies in the middle infrared range from 8 to $14 \mu \mathrm{m}$ ("window" of the atmosphere transparency to electromagnetic radiation). Under these conditions, the relative stability of water clusters depends on external factors, primarily on the temperature.

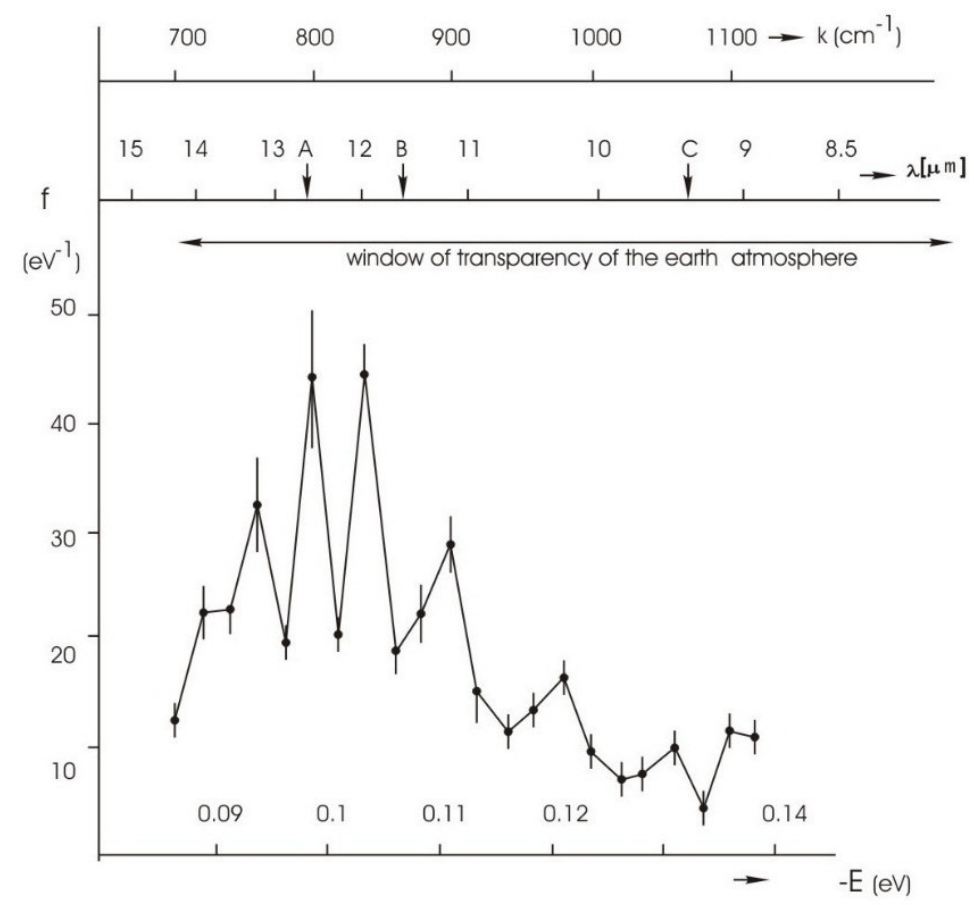

Figure 9: NES-spectrum of deionized water (chemical purity 99.99\%, $\mathrm{pH}=6.5-7.5$, total mineralization 200 $\mathrm{mg} / \mathrm{l}$, electric conductivity $10 \mu \mathrm{S} / \mathrm{cm})$. On the horizontal axis shows the energy of the H...O hydrogen bonds in the associates $-\mathrm{E}(\mathrm{eV})$. The vertical axis - energy distribution function $-\mathrm{f}\left(\mathrm{eV}^{-1}\right) . \mathrm{k}-$ the vibration frequency of the $\mathrm{H}-\mathrm{O}-\mathrm{H}$ atoms $\left(\mathrm{cm}^{-1}\right) ; \lambda$ - wavelength $(\mathrm{mm})$.

It was shown that the $\mathrm{H}_{2} \mathrm{O}$ molecules change their position in clusters depending on the energy of intermolecular H...O hydrogen bonds. The values of the average energy $\left(\mathrm{E}_{\mathrm{H}} \ldots \mathrm{O}\right)$ of hydrogen bonds between the $\mathrm{H}_{2} \mathrm{O}$ molecules in the formation of cluster associates with formula $\left(\mathrm{H}_{2} \mathrm{O}\right)_{\mathrm{n}}$ compile $0.1067 \pm 0.0011 \mathrm{eV}$. As the energy of hydrogen bonds between $\mathrm{H}_{2} \mathrm{O}$ molecules increases up to $-0.14 \mathrm{eV}$, the cluster formation of water becomes "destructuring". In this case, the energy redistribution between the individual $\mathrm{H}_{2} \mathrm{O}$ molecules occures (Figure 10).

All these data indicate that the water is a complex associated non-equilibrium liquid consisting of associative groups containing according to the present data, from 3 to 20 individual $\mathrm{H}_{2} \mathrm{O}$ molecules (Tokmachev et al., 2010). Associates can be perceived as unstable groups (dimmers, trimmers, tetramers, pentamers, hexamers etc.) in which $\mathrm{H}_{2} \mathrm{O}$ molecules are linked by van der Waals forces, dipole-dipole and other charge-transfer interactions, including hydrogen bonding. At room temperature, the degree of association of $\mathrm{H}_{2} \mathrm{O}$ molecules may vary from 2 to 6. In 1993 K. Jordan (USA) (Tsai \& Jordan, 1993) calculated the possible structural modifications of small water clusters consisting of six $\mathrm{H}_{2} \mathrm{O}$ molecules (Figure 10a-c). Subsequently, it was shown that $\mathrm{H}_{2} \mathrm{O}$ molecules capable of hydrogen bonding by forming the structures representing topological 1D rings and 2D chains composed from numerous $\mathrm{H}_{2} \mathrm{O}$ molecules. Interpreting the experimental data, they are considered as pretty stable elements of the structure. According to computer simulations, clusters are able to interact with each other through the exposed protons on the outer surfaces of hydrogen bonds to form new clusters of more complex composition. 


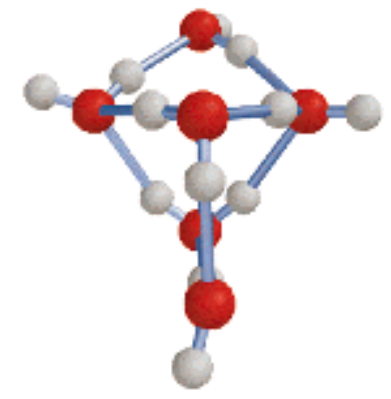

a)

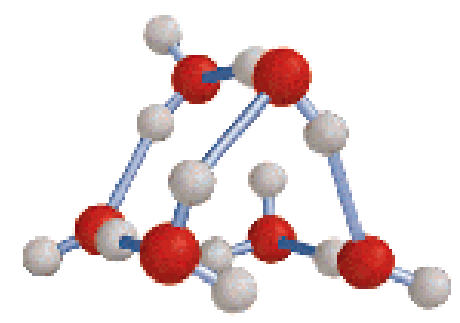

b)

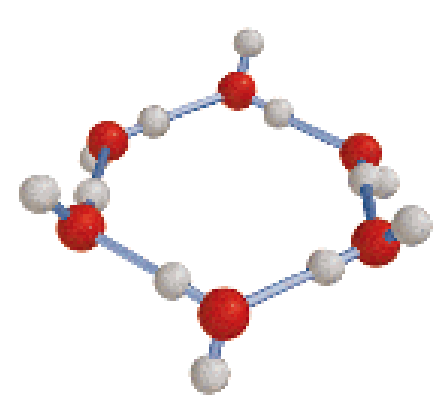

c)

Figure 10: Calculation of small water cluster structures $(\mathrm{a}-\mathrm{c})$ with general formula $\left(\mathrm{H}_{2} \mathrm{O}\right)_{\mathrm{n}}$, where $\mathrm{n}=6($ Tsai \& Jordan, 1993).

In 2000 it was deciphered the structure of the trimmer water, and in 2003 - tetramer, pentamer and the water hexamer (Wang \& Jordan, 2003). Structures of water clusters with formula $\left(\mathrm{H}_{2} \mathrm{O}\right)_{\mathrm{n}}$, where $\mathrm{n}=3-5$, similar

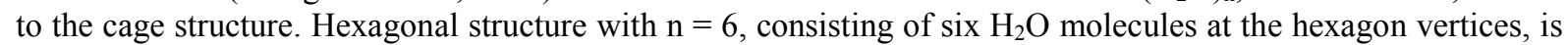
less stable than the cage structure. In the hexagon structure four $\mathrm{H}_{2} \mathrm{O}$ molecules can be cross-linked by hydrogen bonds (Figure 11).


Figure 11: Cluster structure of a trimer, tetramer, pentamer and hexamer of water.

Quantum-chemical calculations of middle size clusters with the general formula $\left(\mathrm{H}_{2} \mathrm{O}\right)_{\mathrm{n}}$, where $\mathrm{n}=6-20$, have shown that the most stable structures are formed by the interaction of tetrameric and pentameric structures (Maheshwary et al., 2001; Choi \& Jordan, 2010). Thus the structures of $\left(\mathrm{H}_{2} \mathrm{O}\right)_{\mathrm{n}}$, where $\mathrm{n}=8,12,16$, and 20 are cubic, and structures $\left(\mathrm{H}_{2} \mathrm{O}\right)_{\mathrm{n}}$ where $\mathrm{n}=10$ and 15 - pentagons (Figure 12). Other structures with $\mathrm{n}=9,11,13,14$, 17,18 and 19 evidently have a mixed composition. Large tetrahedron clusters as $\left(\mathrm{H}_{2} \mathrm{O}\right)_{196},\left(\mathrm{H}_{2} \mathrm{O}\right)_{224},\left(\mathrm{H}_{2} \mathrm{O}\right)_{252}$ (Figure 13) composed from the smaller ones formed a vertex of a $\left(\mathrm{H}_{2} \mathrm{O}\right)_{14}$ tetrahedron are also described (Chaplin, 2011). 

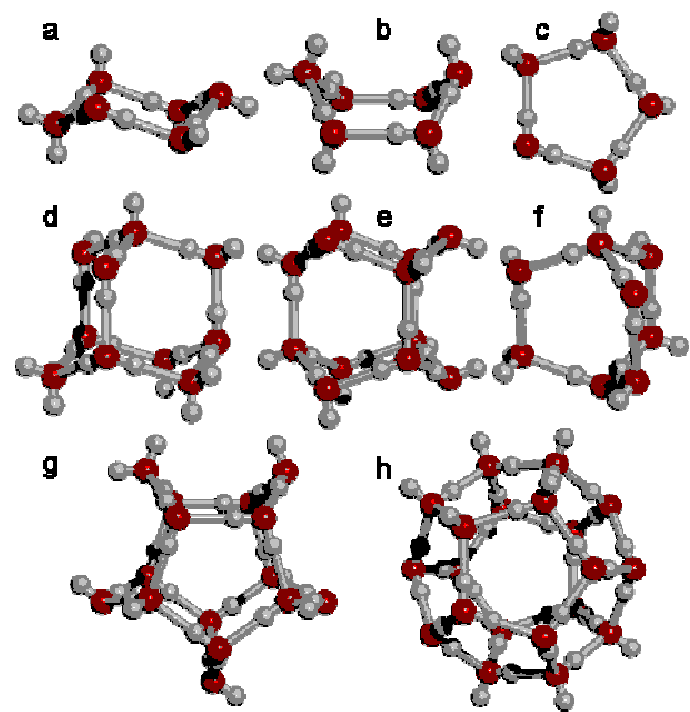

Figure 12: Possible structure and conformation of water clusters $(a-h)$ of the composition $\left(\mathrm{H}_{2} \mathrm{O}\right) \mathrm{n}$, where $\mathrm{n}=5-$ 20 (Chaplin, 2011). The oxygen atoms designated in red, hydrogen atoms - in gray color: $\mathrm{a}, \mathrm{b}-6 ; \mathrm{c}-5 ; \mathrm{d}-10$; $\mathrm{e}-12 ; \mathrm{f}-8 ; \mathrm{g}-15 ; \mathrm{h}-20$ ((M. Chaplin, 2011).



Figure 13: Tetrahedron water clusters $\left(\mathrm{H}_{2} \mathrm{O}\right)_{n}$ with different symmetry $(\mathrm{n}=196,224,252)$ (M. Chaplin, 2011).

It is reasonable that the structure of liquid water should be related to the structure of hexagonal ice, formed from $\mathrm{H}_{2} \mathrm{O}$ tetrahedrons, which exist under atmospheric pressure. In the computer simulation $\mathrm{H}_{2} \mathrm{O}$ tetrahedrons grouped together, to form a variety of 3D-spatial and 1D, 2D-planar structures, the most common of which is hexagonal structure where $6 \mathrm{H}_{2} \mathrm{O}$ molecules (tetrahedrons) are combined into a ring. A similar type of structure is typical for ice $\mathrm{I}_{\mathrm{h}}$ crystals. When ice melts, its hexagonal structure is destroyed, and a mixture of clusters consisting of tri-, tetra-, penta-, and hexamers of water and free $\mathrm{H}_{2} \mathrm{O}$ molecules is formed. Structural studies of these clusters are significantly impeded, since the water is perceived as a mixture of different clusters that are in dynamic equilibrium with each other.

S. Zenin (Russia) calculated a cluster model based on a minimum "quantum" of water (Zenin, 1999), which is a 4 triangular tetrahedron composed of four 12 pentagonal dodecahedrons (Figure 14). The "quantum" consisted of $57 \mathrm{H}_{2} \mathrm{O}$ molecules interacting with each other at the expense of free hydrogen bonds exposed on the surface. Of $57 \mathrm{H}_{2} \mathrm{O}$ molecules in the "quantum" $17 \mathrm{H}_{2} \mathrm{O}$ molecules compose tetrahedral completely hydrophobic, i.e. saturated with four hydrogen bonds in the central carcass, and four dodecahedra on the surface of each there are 10 centers for the formation of hydrogen bond ( $\mathrm{O}-\mathrm{H}$ or $\mathrm{O}$ ). 16 "quanta" form a bigger cluster structure consisted from $912 \mathrm{H}_{2} \mathrm{O}$ molecules similar to a tetrahedron. 


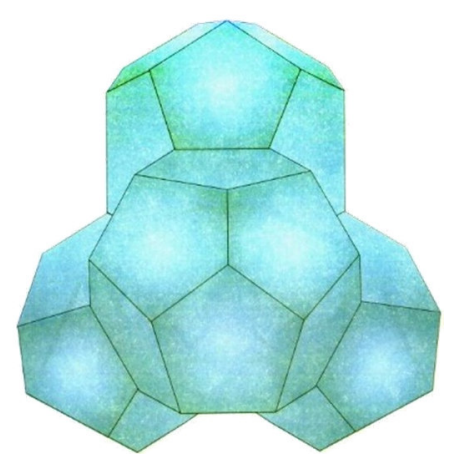

a)

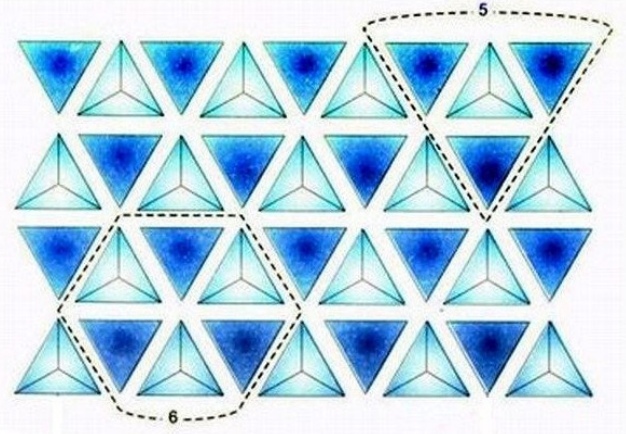

b)

Figure 14: Model of water associates accordung to S.V. Zenin: $a$ ) - assosiate of $57 \mathrm{H}_{2} \mathrm{O}$ molecules, tetrahedron of four dodecahedron (“quantum”); b) - bulk packaging of "quanta" (Zenin, 1999).
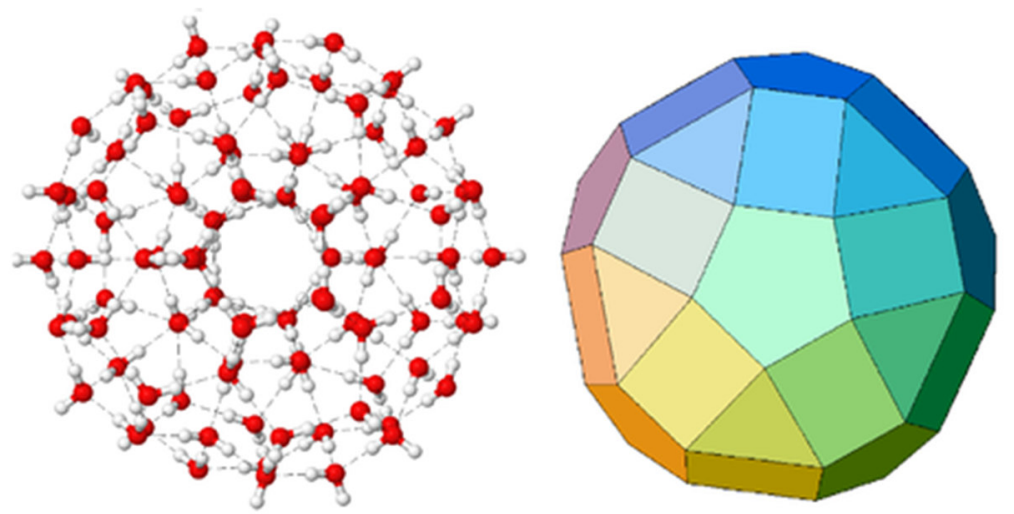

Figure 15: Icosahedron cluster based on $100 \mathrm{H}_{2} \mathrm{O}$ molecules and the underlying structure according to $\mathrm{M}$.

Chaplin's model (Chaplin, 2011).

M. Chaplin (London South Bank University, UK) (Chaplin, 2011) calculated the water structure based on 20 triangular icosahedron (Figure 15). The structure is based on minimal tetrahedral water cluster, consisting of $14 \mathrm{H}_{2} \mathrm{O}$ molecules. Arrangement of 20 of these 14-molecule structures forms an icosahedral network, consisting from $280 \mathrm{H}_{2} \mathrm{O}$ molecules. Each 280-molecule in icosahedral contains several substructures with each $\mathrm{H}_{2} \mathrm{O}$ molecule involved in four hydrogen bonds; two as donor and two as acceptor. 13 overlapping icosahedra may form more large cluster (tricontahedron) consisting from $1820 \mathrm{H}_{2} \mathrm{O}$ molecules, which has twice more $\mathrm{H}_{2} \mathrm{O}$ molecules than in the previous model.

The clusters, evidently, may be rather stable under a certain conditions, and can be obtained in the isolated state within a very short interval of time. There is also a reason to believe that the charged ions stabilize the clusters. Therefore, the clusters can be divided into positively and negatively charged ionic clusters $-\left[\left(\mathrm{H}_{2} \mathrm{O}\right)_{\mathrm{n}}\right]^{+},\left[\left(\mathrm{H}_{2} \mathrm{O}\right)_{\mathrm{n}}\right]^{-}$, and not having a charge - neutral clusters with general formula $\left(\mathrm{H}_{2} \mathrm{O}\right)_{\mathrm{n}}$. Clusters, containing 20 individual $\mathrm{H}_{2} \mathrm{O}$ molecules and a proton in the form of hydronium ion $\mathrm{H}_{3} \mathrm{O}^{+}$("magic" number) form the most stable ionic clusters $\left(\mathrm{H}_{2} \mathrm{O}\right)_{20} \mathrm{H}_{3} \mathrm{O}^{+}$or $\left(\mathrm{H}_{2} \mathrm{O}\right)_{21} \mathrm{H}^{+}$(Figure 16) (Cui et al., 2006). It is assumed that the stability of ionic clusters is due to the special clathrate structure in which $20 \mathrm{H}_{2} \mathrm{O}$ molecules are formed 12 pentagonal dodecahedron, in which cavities is captured the $\mathrm{H}_{3} \mathrm{O}^{+}$ion. It is occurred because of all the clusters only the dodecahedron has large cavities enough to accommodate a bulky $\mathrm{H}_{3} \mathrm{O}^{+}$ion. Subsequently, due to cooperative interactions $\mathrm{H}_{3} \mathrm{O}^{+}$is further able to move to the surface of the cluster and lose a proton $\mathrm{H}^{+}$leading to the formation of hydronium ions like $\mathrm{H}_{5} \mathrm{O}_{2}{ }^{+}$, $\mathrm{H}_{7} \mathrm{O}_{3}{ }^{+}$, and $\mathrm{H}_{9} \mathrm{O}_{4}{ }^{+}$, fixed on the surface of the cluster. These data show the diversity of supposed water structures and the complexity of molecular interactions between the different water clusters, the nature of which we are only beginning to understand. 


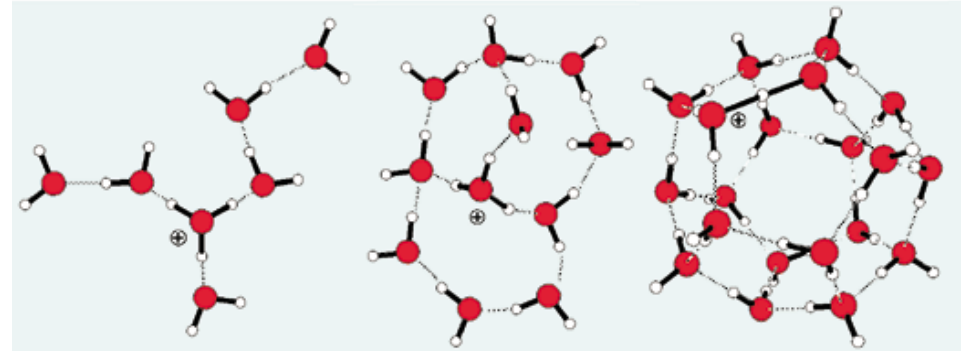

Figure 16: Formation of ionic clusters $\left(\mathrm{H}_{2} \mathrm{O}\right)_{20} \mathrm{H}_{3} \mathrm{O}^{+}$or $\left(\mathrm{H}_{2} \mathrm{O}\right)_{21} \mathrm{H}^{+}$with captured hydronium ion $\mathrm{H}_{3} \mathrm{O}^{+}$.

\section{Methods of Study Water Clusters}

Cluster structures in water calculated theoretically on computer were confirmed by ${ }^{1} \mathrm{H}-\mathrm{NMR}$, IR, Raman, Compton scattering, EXAFS-spectroscopy and X-ray diffraction (Ignatov, 2005; Mosin \& Ignatov, 2011). Information obtained with using the modern detection methods corresponds to femtosecond time, i.e instantaneous dynamics of intermolecular interactions in the molecular scale. The presence of hydrogen bonding causes the noticable effect on vibrational and ${ }^{1} \mathrm{H}-\mathrm{NMR}$ spectra. In ${ }^{1} \mathrm{H}-\mathrm{NMR}$ the chemical shift of the proton involved in the hydrogen bonding shifts about $0.01 \mathrm{ppm}$ reducing strength of hydrofen bonding while the temperature is raised (Yamaguchi et al., 2001). Increased extent of hydrogen bonding within clusters results in a similar effect; the higher chemical shifts with greater cooperativity, the shorter hydrogen bonded $\mathrm{O}-\mathrm{H} . . . \mathrm{O}$ distances. ${ }^{1} \mathrm{H}$ peaks shift to greater ppm with increasing hydrogen bonding strength.

In IR-spectroscopy the characteristic vibration frequency bands containing hydrogen are reduced in spectra if hydrogen atom is included in the hydrogen bonding. Infrared absorption bands, such as OH-groups are much expanded when the hydrogen bond is formed, and their intensity increases. The main stretching band in liquid water is shifted to a lower fequency $\left(\mathrm{v}_{3}, 3480 \mathrm{~cm}^{-1}\right.$ and $\left.\mathrm{v}_{1}, 3270 \mathrm{~cm}^{-1}\right)$, while the bending frequency $\left(\mathrm{v}_{2}\right.$, $1640 \mathrm{~cm}^{-1}$ ) increased by hydrogen bonding (Ohno et al., 2005). Increased strength of hydrogen bonding shifts the stretch vibration to lower frequencies with greatly increased intensity in the infrared due to the increased dipoles. With raising the temperature the stretch vibrations shift to higher frequency, while the intramolecular vibrations shift to lower frequencies (Ignatov, 2012; Ignatov \& Mosin, 2013b). Hydrogen bond energy lies in the range of $2.3 \mathrm{kcal} / \mathrm{mole}$ for the $\mathrm{N}-\mathrm{H}$...O-bonds up to $7.0 \mathrm{kcal} / \mathrm{mol}$ for the bonds with hydrogen fluoride $\mathrm{F}-\mathrm{H} . . . \mathrm{F}$. The strength of the hydrogen bonding depends on the cooperative/anticooperative character of the surrounding hydrogen bonds with the strongest hydrogen bonds giving the lowest vibrational frequencies.

In X-ray absorption spectroscopy (EXAFS-spectroscopy) X-ray radiation excites the electrons of the inner shell of an oxygen atom in $\mathrm{H}_{2} \mathrm{O}$ molecules and stipulates their transition onto unoccupied upper electronic levels in the molecules (Wernet et al., 2004). Probability of electron transitions and characteristics of the absorption contour depends mostly on the molecular environment. This allows by varying the energy of the X-rays to study the distribution of associations for $\mathrm{HOH}_{\ldots} . . \mathrm{OH}_{2}$ bond judging on lengths and angles of the covalently bonded hydrogen atom in the molecule. EXAFS spectrum near the oxygen atom is also sensitive to hydrogen bonding. This method is used to obtain information about the molecular structure of water in the first coordination sphere. Since the time of excitation of electrons is much smaller than the vibrational motions in liquids, X-ray probe of the electronic structure provides information about the instantaneous changes of configurations of the water structure.

Diffraction techniques (X-ray and neutron diffraction) on liquid water allow to calculate the function of density radial distribution $(\mathrm{O}$ or $\mathrm{H})$ and the probability of detection of $\mathrm{H}_{2} \mathrm{O}$ molecules at a certain distance from a randomly chosen individual $\mathrm{H}_{2} \mathrm{O}$ molecule (Tokushima et al., 2008). This allows to detect the irregularities in water by constructing the radial distribution function, i.e. the distance between the atoms of $\mathrm{O}, \mathrm{H}$, and $\mathrm{O}-\mathrm{H}$ in $\mathrm{H}_{2} \mathrm{O}$ molecule and its nearest neighbors. Thus, the distribution of the distances between the oxygen atoms at a room temperature, gives three major peaks measured at $2.8,4.5$ and $6,7 \AA$. The first maximum corresponds to the distance to the nearest neighbor and its value is approximately equal to the length of the hydrogen bond. The second maximum is close to the average edge length of a tetrahedron, as $\mathrm{H}_{2} \mathrm{O}$ molecules in the crystalline structure of ice $\mathrm{I}_{\mathrm{h}}$ arranged at the vertices of the tetrahedron allocated around the center of the molecule. The third peak, expressed very weakly, corresponds to the distance to the third and more distant neighboring $\mathrm{H}_{2} \mathrm{O}$ molecules on the hydrogen network. In 1970 I.S. Andrianov and I.Z. Fisher calculated the distance up to the eighth of the neighboring $\mathrm{H}_{2} \mathrm{O}$ molecule; the distance to the fifth the neighboring $\mathrm{H}_{2} \mathrm{O}$ molecule turned out to be $3 \AA$, and to the sixth molecule - 3,1 $\AA$. This allowed draw conclusions about the geometry of hydrogen bonds and farther surroundings of $\mathrm{H}_{2} \mathrm{O}$ molecules.

Another method for structural studies - neutron diffraction is similar to X-ray diffraction. However, because the neutron scattering lengths vary slightly among different atoms, this method is limited in the case of the isomorphous substitution of hydrogen atoms in $\mathrm{H}_{2} \mathrm{O}$ molecule by deuterium (D). In practice generally operate 
with a crystal whose molecular structure is approximately defined by other methods. Then, it is measured the intensity of the neutron diffraction of this crystal. From these results, the Fourier transform is carried out; the measured neutron intensity and phase are using for calculation. Then, on the resultant Fourier map hydrogen and deuterium atoms are represented with much greater atomic weight than on the electron density map, as the contribution of these atoms in neutron scattering is essentially big. On the resulting density map is determined the arrangement of hydrogen ${ }^{1} \mathrm{H}$ (negative density) and deuterium $\mathrm{D}$ (positive density) atoms. A variation of the method consists in that the crystal of an ordinary protonated water $\left(\mathrm{H}_{2} \mathrm{O}\right)$ before measurements kept in 99.9 at.\% of heavy water $\left(\mathrm{D}_{2} \mathrm{O}\right)$. In this case the neutron diffraction can not only establish the localization of the hydrogen atoms, as well as to identify those protons that can be exchanged by deuterium, that is particularly important for the study of isotopic (H-D) exchange. Such information in some cases may help confirm the correctness of the water structure established by other methods.

The clusters formed of $\mathrm{D}_{2} \mathrm{O}$ are some more stable and resistant than those ones from $\mathrm{H}_{2} \mathrm{O}$ due to isotopic effects of deuterium caused by 2 -fold increasing nuclear mass of deuterium (molecular mass of $\mathrm{D}_{2} \mathrm{O}$ is more by $11 \%$ than that of $\mathrm{H}_{2} \mathrm{O}$ ). The structure of $\mathrm{D}_{2} \mathrm{O}$ molecule is the same, as that of $\mathrm{H}_{2} \mathrm{O}$, with small distinction in values of lengths of covalent bonds. $\mathrm{D}_{2} \mathrm{O}$ crystals have the same structure as a conventional ice $\mathrm{I}_{\mathrm{h}}$, the difference in unit cell size is very insignificant $(0.1 \%)$. But they are heavy $\left(0.982 \mathrm{~g} / \mathrm{cm}^{3}\right.$ at $0^{0} \mathrm{C}$ over $0.917 \mathrm{~g} / \mathrm{cm}^{3}$ for conventional ice). $\mathrm{D}_{2} \mathrm{O}$ boils at $101.44{ }^{\circ} \mathrm{C}$, freezes at $3,82^{\circ} \mathrm{C}$, has density at $20^{\circ} \mathrm{C} 1.105 \mathrm{~g} / \mathrm{cm}^{3}$, and the maximum density occurs not at the $3.89^{\circ} \mathrm{C}$, as for $\mathrm{H}_{2} \mathrm{O}$, but at $11.2^{\circ} \mathrm{C}\left(1.106 \mathrm{~g} / \mathrm{cm}^{3}\right)$ (Table 3). The mobility of $\mathrm{D}_{3} \mathrm{O}^{+}$ion on $28.5 \%$ lower than that of $\mathrm{H}_{3} \mathrm{O}^{+}$ion and $\mathrm{OD}^{-}$ion $-39.8 \%$ lower than that of $\mathrm{OH}^{-}$ion, the constant of ionization of $\mathrm{D}_{2} \mathrm{O}$ is less than the constant of ionization of $\mathrm{H}_{2} \mathrm{O}$, which means that $\mathrm{D}_{2} \mathrm{O}$ has a bit more hydrophobic properties than $\mathrm{H}_{2} \mathrm{O}$. All these effects lead that the hydrogen bonds formed by deuterium atoms differ in strength and energy from ordinary hydrogen bonds (O-H length $1.01 \AA$, O-D length $0.98 \AA$, D-O-D angle $\left.106^{0}\right)$. Commonly used molecular models use $\mathrm{O}-\mathrm{H}$ lengths $\sim 0.955 \AA$ and $1.00 \AA$ and $\mathrm{H}-\mathrm{O}-\mathrm{H}$ angles from $\sim 105.5^{0}$ to $\sim 109.4^{0}$. The substitution of $\mathrm{H}$ with $\mathrm{D}$ atom affects the stability and geometry of hydrogen bonds in apparently rather complex way and may, through the changes in the hydrogen bond zero-point vibrational energies, alter the conformational dynamics of hydrogen (deuterium)-bonded structures of associates. In general, isotopic effects stabilize hydrogen bond with participation of deuterium, resulting in somewhat greater stability of associates (clusters) formed from $\mathrm{D}_{2} \mathrm{O}$ molecules (Mosin \& Ignatov, 2013b).

According to the international SMOW standard the absolute content of D (isotopic shift, $\delta, \mathrm{ppm}$ ) in sea water: $\mathrm{D} / \mathrm{H}=(155.76 \pm 0.05) \cdot 10^{-6}(155.76 \mathrm{ppm})$ (Ignatov \& Mosin, 2013d). For SLAP standard isotopic shifts for $\mathrm{D}$ in seawater: $\mathrm{D} / \mathrm{H}=89 \cdot 10^{-6}(89 \mathrm{ppm})$. The content of the lightest isotopologue $-\mathrm{H}_{2}{ }^{16} \mathrm{O}$ in water corresponding to SMOW standard is $997.0325 \mathrm{~g} / \mathrm{kg}(99.73 \mathrm{~mol} \%$ ), and for SLAP standard - $997.3179 \mathrm{~g} / \mathrm{kg}(99.76 \mathrm{~mol} . \%)$. In surface waters, the ratio $\mathrm{D} / \mathrm{H}=(1.32-1.51) \cdot 10^{-4}$, while in the coastal seawater $-(1.55-1.56) \cdot 10^{-4}$.

Table 3: Changes in the physical properties of water with its isotopic substitution with deuterium

\begin{tabular}{|l|l|l|}
\hline Physical properties & $\mathrm{H}_{2}{ }^{16} \mathrm{O}$ & $\mathrm{D}_{2}{ }^{16} \mathrm{O}$ \\
\hline Density at $+20{ }^{0} \mathrm{C}, \mathrm{g} / \mathrm{cm}^{3}$ & 0.997 & 1.105 \\
\hline Temperature of maximum density, ${ }^{0} \mathrm{C}$ & 3.98 & 11.24 \\
\hline Melting point under $1 \mathrm{~atm},{ }^{0} \mathrm{C}$ & 0 & 3.81 \\
\hline Boiling point temperature at $1 \mathrm{~atm},{ }^{0} \mathrm{C}$ & 100.00 & 101.42 \\
\hline The vapor pressure at $100{ }^{0} \mathrm{C}, \mathrm{mm} \mathrm{Hg}$ & 760.00 & 721.60 \\
\hline Viscosity at $+20{ }^{0} \mathrm{C}, \mathrm{cP}$ & 1.002 & 1.47 \\
\hline
\end{tabular}

As a result of experiments on quasi-elastic neutron scattering was measured the most important parameter - the coefficient of self-diffusion of water at different temperatures and pressures. To analyze the self-diffusion coefficient on quasi-elastic neutron scattering, it is necessary to know the character of moving of molecules. If they move in accordance with the "jump-wait" model, then the "settled" life time (the time between jumps) of $\mathrm{H}_{2} \mathrm{O}$ molecule compiles 3.2 ps. The newest methods of femtosecond laser spectroscopy allow to estimate the lifetime of the broken hydrogen bonds: a proton needs 200 fs to find a partner.

The studying the full details of the structure of associative elements in water can be made, considering all the parameters by computer simulation or numerical experiment (Figure 17). For this in a given space is chosen random ensemble of $\mathrm{n}_{2} \mathrm{O}$ molecules and are optimal parameters - the energy of interatomic interactions, bond length, the arrangement of atoms and molecules, the most consistent with the diffraction data. Data thus obtained are then extrapolated to the actual water structure, and further used to calculate thermodynamic parameters. Data obtained by computer experiments, show that the nature of the thermal motion of the molecules in the liquids corresponds on the whole to a vibration of the individual $\mathrm{H}_{2} \mathrm{O}$ molecules near the equilibrium centers, with occasional jumps up to the new position. 


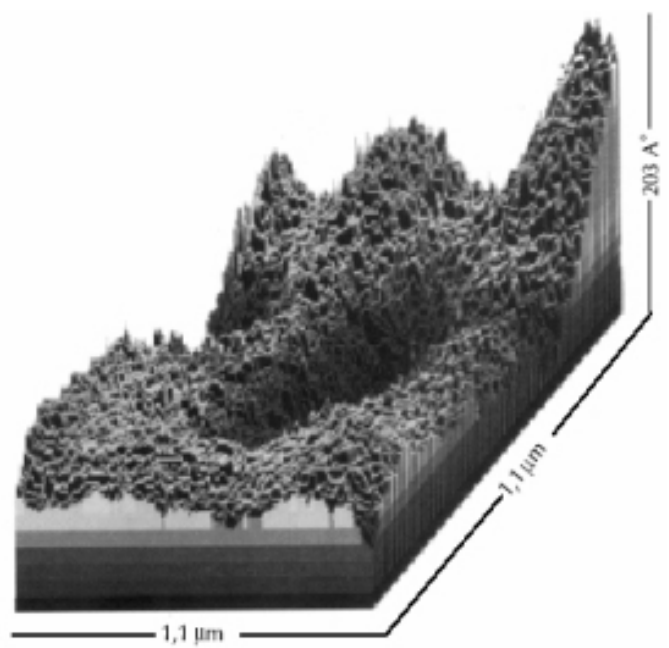

Figure 17: Cluster structure of water in a numerical experiment

The comparative analysis of IR-spectra of $\mathrm{H}_{2} \mathrm{O}$ solutions and its deuterated analogues $\left(\mathrm{D}_{2} \mathrm{O}, \mathrm{HDO}\right)$ is of considerable interest for biophysical studies, because at changing of the atomic mass of hydrogen by deuterium atoms in $\mathrm{H}_{2} \mathrm{O}$ molecule their interaction will also change, although the electronic structure of the molecule and its ability to form H-bonds, however, remains the same. The IR spectra of water usually contain three absorption bands, which can be identified as 1 - absorption band of the stretching vibration of $\mathrm{OH}^{-}$group; 2 - absorption band of the first overtone of the bending vibration of the molecule HDO; 3 - absorption band of stretching vibration of $\mathrm{OD}^{-}$group. $\mathrm{OH}^{-}$group is able to absorb much infrared radiation in the infrared region of the IR-spectrum. Because of its polarity, these groups typically react with each other or with other polar groups to form intra-and intermolecular hydrogen bonds. The hydroxyl groups not involved in formation of hydrogen bonds are usually given the narrow bands in IR spectrum and the associated groups - broad intense absorption bands at lower frequencies. The magnitude of the frequency shift is determined by the strength of the hydrogen bond. Complication of the IR spectrum in the area of $\mathrm{OH}^{-}$stretching vibrations can be explained by the existence of different types of associations, a manifestation of overtones and combination frequencies of $\mathrm{OH}^{-}$groups in hydrogen bonding, as well as the proton tunneling effect (on the relay mechanism. Such complexity makes it difficult to interpret the IR spectrum and partly explains the discrepancy in the literature available on this subject.

The local maximums in IR-spectra reflect vibrational-rotational transitions in the ground electronic state; the substitution with deuterium changes the vibrational-rotational transitions in $\mathrm{H}_{2} \mathrm{O}$ molecule that is why it appears other local maximums in IR-spectra. In the water vapor state, the vibrations involve combinations of symmetric stretch $\left(v_{1}\right)$, asymmetric stretch $\left(v_{3}\right)$ and bending $\left(v_{2}\right)$ of the covalent bonds with absorption intensity $\left(\mathrm{H}_{2} \mathrm{O}\right) v_{1} ; v_{2} ; v_{3}$ $=2671 ; 1178.4 ; 2787.7 \mathrm{~cm}^{-1}$. For liquid water absorption bands are observed in other regions of the IR-spectrum, the most intense of which are located at $2100, \mathrm{~cm}^{-1}$ and $710-645 \mathrm{~cm}^{-1}$. For $\mathrm{D}_{2} \mathrm{O}$ molecule these ratio compiles 2723.7, 1403.5 and $3707.5 \mathrm{~cm}^{-1}$, while for HDO molecule - 2671.6, 1178.4 and $2787.7 \mathrm{~cm}^{-1}$. HDO (50 mole\% $\mathrm{H}_{2} \mathrm{O}+50$ mole $\%{ }^{2} \mathrm{H}_{2} \mathrm{O} ; \sim 50 \% \mathrm{HDO}, \sim 25 \% \mathrm{H}_{2} \mathrm{O}, \sim 25 \% \mathrm{D}_{2} \mathrm{O}$ ) has local maxima in IR-spectra at $3415 \mathrm{~cm}^{-1}, 2495$ $\mathrm{cm}^{-1} 1850 \mathrm{~cm}^{-1}$ and $1450 \mathrm{~cm}^{-1}$ assigned to $\mathrm{OH}^{-}$-stretch, $\mathrm{OD}^{-}$-stretch, as well as combination of bending and libration and HDO bending respectively.

In the IR-spectrum of liquid water absorbance band considerably broadened and shifted relative to the corresponding bands in the spectrum of water vapor. Their position depends on the temperature (Ignatov \& Mosin, $2013 \mathrm{~b}$ ). The temperature dependence of individual spectral bands of liquid water is very complex (Zelsmann, 1995). Furthermore, the complexity of the IR-spectrum in the area of $\mathrm{OH}^{-}$stretching vibration can be explained by the existence of different types of $\mathrm{H}_{2} \mathrm{O}$ associations, manifestation of overtones and composite frequencies of $\mathrm{OH}^{-}$ groups in the hydrogen bonds, and the tunneling effect of the proton (for relay mechanism) (Yukhnevitch, 1973). Such complexity makes it difficult to interpret the spectrum and partly explains the discrepancy in the literature available on this subject.

In liquid water and ice the IR-spectra are far more complex than those ones of the vapor due to vibrational overtones and combinations with librations (restricted rotations, e.g. rocking motions). These librations are due to the restrictions imposed by hydrogen bonding (minor $\mathrm{L}_{1}$ band at $395.5 \mathrm{~cm}^{-1}$; major $\mathrm{L}_{2}$ band at $686.3 \mathrm{~cm}^{-1}$; for liquid water at $0{ }^{0} \mathrm{C}$, the absorbance of $\mathrm{L}_{1}$ increasing with increasing temperature, while $\mathrm{L}_{2}$ absorbance decreases but broadens with reduced wave number with increasing temperature (Brubach et al., 2005). The IR spectra of liquid water usually contain three absorbance bands, which can be identified on absorption band of the stretching vibration of $\mathrm{OH}^{-}$group; absorption band of the first overtone of the bending vibration of the molecule HDO and absorption band of stretching vibration of $\mathrm{OD}^{-}$group (Max \& Chapados, 2009). Hydroxyl group $\mathrm{OH}^{-}$is able to absorb much infrared radiation in the infrared region of the IR-spectrum. Because of its polarity, these groups 
typically react with each other or with other polar groups to form intra-and intermolecular hydrogen bonds. The hydroxyl groups, which are not involved in formation of hydrogen bonds usually produce the narrow bands in IR spectrum, while the associated groups - broad intense absorbance bands at lower frequencies. The magnitude of the frequency shift is determined by the strength of the hydrogen bond. Complication of the IR spectrum in the area of $\mathrm{OH}^{-}$stretching vibrations can be explained by the existence of different types of associations of $\mathrm{H}_{2} \mathrm{O}$ molecules, a manifestation of overtones and combination frequencies of $\mathrm{OH}^{-}$groups in hydrogen bonding, as well as the proton tunneling effect (on the relay mechanism).

Assignment of main absorption bands in the IR-spectrum of liquid water is given in Table 4 . The IR spectrum of $\mathrm{H}_{2} \mathrm{O}$ molecule was examined in detail from the microwave till the middle $\left(4-17500 \mathrm{~cm}^{-1}\right)$ visible region and the ultraviolet region - from $200 \mathrm{~nm}^{-1}$ to ionization limit at $98 \mathrm{~nm}^{-1}$ (Walrafen, 1972). In the middle visible region at $4-7500 \mathrm{~cm}^{-1}$ are located rotational spectrum and the bands corresponding to the vibrationalrotational transitions in the ground electronic state. In the ultraviolet region (200 to $\left.98 \mathrm{~nm}^{-1}\right)$ are located bands corresponding to transitions from the excited electronic states close to the ionization limit in the electronic ground state. The intermediate region of the IR-spectrum - from $570 \mathrm{~nm}$ to $200 \mathrm{~nm}$ corresponds to transitions to higher vibrational levels of the ground electronic state.

The results of IR-spectroscopy with device Infra Spec VFA-IR show that at $4.1 \mu \mathrm{m}$, even at low concentrations of deuterium of 0.35 and $0.71 \%$, there is observed a decline in the local maximums relative to the local maximum of $100 \%$ pure water (the local maximums in IR-spectra reflect vibrational-rotational transitions in the ground electronic state because at changing the atomic mass of hydrogen and deuterium atoms in the water molecule their interaction will also change, although the electronic structure of the molecule and its ability to form $\mathrm{H}$-bonds, however, remains the same; with the substitution with deuterium the vibrational-rotational transitions are changed, that is why it appears other local maximums in IR-spectra.

Table 4: The assignment of main frequencies in IR-spectra of $\mathrm{H}_{2} \mathrm{O}$ and $\mathrm{D}_{2} \mathrm{O}$

\begin{tabular}{|l|c|c|c|c|}
\hline \multicolumn{4}{|c|}{ Main vibrations of liquid $\mathrm{H}_{2} \mathrm{O}$ and ${ }^{2} \mathrm{H}_{2} \mathrm{O}$} \\
\hline Vibration(s) & \multicolumn{2}{|c|}{$\mathrm{H}_{2} \mathrm{O}\left(\mathrm{t}=25^{0} \mathrm{C}\right)$} & \multicolumn{2}{c|}{$\mathrm{D}_{2} \mathrm{O}\left(\mathrm{t}=25^{0} \mathrm{C}\right)$} \\
\cline { 2 - 5 } & $v, \mathrm{~cm}^{-1}$ & $\mathrm{E}_{0}, \mathrm{M}^{-1} \mathrm{~cm}^{-1}$ & $v, \mathrm{~cm}^{-1}$ & 1210 \\
\hline $\begin{array}{l}\text { Spinning } \\
\text { deformation } v_{2}\end{array}$ & $780-1645$ & 21.65 & $\mathrm{M}^{-1} \mathrm{~cm}^{-1}$ \\
\hline Composite $v_{1}+v_{2}$ & 2150 & 3.46 & 1555 & 17.10 \\
\hline $\begin{array}{l}\text { Valence symmetrical } v_{1}, \\
\text { valence asymmetrical } v_{3}, \\
\text { and overtone 2 } v_{2}\end{array}$ & $3290-3450$ & 100.65 & 2510 & 69.70 \\
\hline
\end{tabular}

At further transition from $\mathrm{H}_{2} \mathrm{O}$ monomers to $\mathrm{H}_{4} \mathrm{O}_{2}$ dimmer and $\mathrm{H}_{6} \mathrm{O}_{3}$ trimmer absorption maximum of valence stretching vibrations of the $\mathrm{O}-\mathrm{H}$ bond is shifted toward lower frequencies $\left(v_{3}=3490 \mathrm{~cm}^{-1}\right.$ and $v_{1}=3280$ $\mathrm{cm}^{-1}$ ) (Eisenberg \& Kauzmann, 1969) and the bending frequency increased $\left(v_{2}=1644 \mathrm{~cm}^{-1}\right)$ because of hydrogen bonding. The increased strength of hydrogen bonding typically shifts the stretch vibration to lower frequencies (red-shift) with greatly increased intensity in the infrared due to the increased dipoles. In contrast, for the deformation vibrations of the $\mathrm{H}-\mathrm{O}-\mathrm{H}$, it is observed a shift towards higher frequencies. Absorption bands at 3546 and $3691 \mathrm{~cm}^{-1}$ were attributed to the stretching modes of the dimmer $\left[\left(\mathrm{H}_{2} \mathrm{O}\right)_{2}\right]$. These frequencies are significantly lower than the valence modes of $v_{1}$ and $v_{3}$ vibrations of isolated $\mathrm{H}_{2} \mathrm{O}$ molecules at 3657 and $3756 \mathrm{~cm}^{-1}$ respectively). The absorption band at $3250 \mathrm{~cm}^{-1}$ represents overtones of deformation vibrations. Among frequencies between 3250 and $3420 \mathrm{~cm}^{-1}$ is possible Fermi resonance (this resonance is a single substitution of intensity of one fluctuation by another fluctuation when they accidentally overlap each other). The absorption band at $1620 \mathrm{~cm}^{-1}$ is attributed to the deformation mode of the dimmer. This frequency is slightly higher than the deformation mode of the isolated $\mathrm{H}_{2} \mathrm{O}$ molecule $\left(1596 \mathrm{~cm}^{-1}\right)$. A shift of the band of deformation vibration of water in the direction of high frequencies at the transition from a liquid to a solid state is attributed by the appearance of additional force, preventing O-H bond bending. Deformation absorption band in IR-spectrum of water has a frequency at $1645 \mathrm{~cm}^{-}$ ${ }^{1}$ and very weak temperature dependence. It changes little in the transition to the individual $\mathrm{H}_{2} \mathrm{O}$ molecule at a frequency of $1595 \mathrm{~cm}^{-1}$. This frequency is found to be sufficiently stable, while all other frequencies are greatly affected by temperature changes, the dissolution of the salts and phase transitions. It is believed that the persistence of deformation oscillations is stipulated by processes of intermolecular interactions, e.g. by the change in bond angle as a result of interaction of $\mathrm{H}_{2} \mathrm{O}$ molecules with each other, as well as with cations and anions.

Thus the study of the characteristics of the IR spectrum of water allows to answer the question not only on the physical parameters of the molecule and the covalent bonds at isotopic substitution with deuterium, but also to make a certain conclusion on associative environment in water. The latter fact is important in the study of structural and functional properties of water associates and its isotopomers at the isotopic substitution with deuterium. The substitution of $\mathrm{H}$ with $\mathrm{D}$ affects the stability and geometry of hydrogen bonds in an apparently rather complex way and may, through the changes in the hydrogen bond zero-point vibration energies, alter the conformational dynamics of hydrogen (deuterium)-bonded structures of macromolecules as DNA and proteins in 
$\mathrm{D}_{2} \mathrm{O}$ (Cleland, 1976).

\section{Conclusion}

The experimental data obtained during the last years suggest that water is a complex dynamic associative system, consisting of tens and possibly hundreds individual $\mathrm{H}_{2} \mathrm{O}$ molecules binding by multiple intermolecular hydrogen bonds, being in a state of dynamic equilibrium. Up till now is scientifically proven the existence of associative water clusters with general formula $\left(\mathrm{H}_{2} \mathrm{O}\right)_{n}$, where $\mathrm{n}=3-20$. Although calculated structural models explain pretty well many anomalous properties of water and being in a good agreement with the experimental data on the diffraction of X-rays and neutrons, Raman, Compton scattering and EXAFS-spectroscopy, they are the most difficult to agree with the dynamic properties of water - flow, viscosity and short relaxation times, which are measured by picoseconds.

\section{Referenses}

Antonov A. \& Galabova T. (1992) Reports from the $6^{\text {th }}$ Nat. Conference of Biomedical Physics and Engineering. Sofia.

Antonov A. (2005) Research of the Nonequilibrium Processes in the Area in Allocated Systems. Diss. Thesis Doctor of Physical Sciences, Sofia: Blagoevgrad.

Arunan E., Desiraju G.R., Klein R.A. et all. (2011) Definition of the hydrogen bond. Pure Appl. Chem., 83(8), 1637-1641.

Bai J., Wang J. \& Zeng C. (2006) Multiwalled Ice Helixes and Ice Nanotubes. Proc. Natl. Acad. Sci., 3, $104-117$. Bartha F., Kapuy O., Kozmutza C \& Van Alsenoy C. (2003) Analysis of weakly bound structures: hydrogen bond and the electron density in a water dimmer. J. Mol. Struct. (Theochem) 666, 117-122.

Bernal J.D. \& Fowler R.H. (1933) A Theory of Water and Ionic Solutions, with Particular Reference to Hydrogen and Hydroxyl Ions.J. Chem. Phys., 1, 515-548.

Brubach, J.B., Mermet, A., Filabozzi, A., Gerschel, A. \& Roy, P. (2005) Signatures of the hydrogen bonding in the infrared bands of water. J. Chem. Phys., 122: 184509.

Chaplin M. (2011) The Water Molecule, Liquid Water, Hydrogen Bonds and Water Networks / in: Water The Forgotten Biological Molecule, D.Le Bihan \& H.Fukuyama (eds.), Singapore: Pan Stanford Publishing Pte. Ltd. Choi T.N. \& Jordan K.D. (2010) Application of the SCC-DFTB Method to $\mathrm{H}^{+}\left(\mathrm{H}_{2} \mathrm{O}\right)_{6}, \mathrm{H}^{+}\left(\mathrm{H}_{2} \mathrm{O}\right)_{21}$, and $\mathrm{H}^{+}\left(\mathrm{H}_{2} \mathrm{O}\right)_{22}$. J. Phys. Chem. B, 114, 6932-6936.

Christie R.A. \& Jordan K.D. (2005) Monte Carlo Simulations of the Finite Temperature Properties of $\left(\mathrm{H}_{2} \mathrm{O}\right)_{6} /$ in: Theory and Applications of Computational Chemistry: The First 40 Years, A Volume of Technical and Historical Perspectives, Ed. C.E. Dykstra, G.Frenking, K.S. Kim \& G. Scuseria. New York: Theochem.

Cleland W.N. (1976) Isotope effects on enzyme-catalyzed reactions. Ed. W.N. Cleland, M.N. O'Leary, D.D. Northrop. Baltimore, London, Tokyo, University Park Press, 303 p.

Cui J., Liu H. \& Jordan K.D. (2006) Theoretical Characterization of the $\left(\mathrm{H}_{2} \mathrm{O}\right)_{21}$ Cluster: Application of an n-body Decomposition Procedure. J. Phys. Chem., 110, 18872-18878.

Domrachev G.A. \& Selivanovsky D.A. (1990) The Role of Sound and Liquid Water as Dynamically Unstable Polymer System in Abiogenous Production of Oxygen and the Origin of Life on the Earth, Preprint N 1'90. Gorky: Inst. of Organometallic Chem. of the USSR Acad. Sci. [in Russian].

Eisenberg, D. \& Kauzmann, W. (1969) The Structure and Properties of Water. Oxford University Press, London. Frenkel Y.I. (1975) Kinetic theory of liquids. Leningrag: Nauka [in Russian].

George A.J. (1997) An Introduction to Hydrogen Bonding (Topics in Physical Chemistry). London: Oxford University Press.

Goryainov S.V. (2012) A model of phase transitions in double-well Morse potential: Application to hydrogen bond. Physica B, 407, 4233-4237.

Henry S., Frank S. \& Wen-Yang Wen. (1957) Ion-solvent interaction. Structural Aspects of Ion-solvent Interaction in Aqueous Solutions: a Suggested Picture of Water Structure. Discuss. Faraday Soc., 24, 133-140.

Ignatov I. (2005) Energy Biomedicine, Structure of Water. Sofia, Moscow, Munich: Gea-Libris, ICH.

Ignatov, I. (2012) Origin of life and living matter in hot mineral water, Conference on the Physics, Chemistry and Biology of Water, Vermont Photonics, USA.

Ignatov I. \& Mosin O.V. (2013a) Isotopic Composition of Water and its Temperature in Modeling of Primordial Hydrosphere Experiments. Nauchnoe Obozrenie, 1, 17-27 [in Russian].

Ignatov I. \& Mosin O.V. (2013b) Possible Processes for Origin of Life and Living Matter with modeling of Physiological Processes of Bacterium Bacillus Subtilis in Heavy Water us Model System. Journal of Natural Sciences Research, 83(8), 132-139.

Isaacs E.D., Shukla A., Platzman P.M, et all. (2000) Compton scattering evidence for covalency of the hydrogen bond in ice, J. Phys. Chem. Solids, 61, 403-406.

Keutsch F. \& Saykally R. (2011) Water Clusters: Untangling the Mysteries of the Liquid, One Molecule at a Time. 
PNAS, 98(19), 105330-10540.

Liu K., Cruzan J.D. \& Saykally R.J. (1996) Water clasters. Science Magazine, 271(5251), 929-933.

Loboda O. \& Goncharuk V. (2010) Theoretical study on icosahedral water clusters. Chemical Physics Letters, 484(4-6), 144-147.

Luck W., Schiöberg D. \& Ulrich S. (1980) Infared Iinvestigation of Water Structure in Desalination Membranes. J. Chem. Soc. Faraday Trans., 2(76), 136-147.

Maheshwary S., Patel N., Sathyamurthy N., Kulkarni A.D. \& Gadre S.R. (2001) Structure and Stability of Water Clusters $\left(\mathrm{H}_{2} \mathrm{O}\right)_{\mathrm{n}}, \mathrm{n}=8-20$ : An Ab Initio Investigation. J. Phys. Chem., 105, 10525-10537.

Max, J.J. \& Chapados, C. (2009) Isotope effects in liquid water by infrared spectroscopy. III. $\mathrm{H}_{2} \mathrm{O}$ and $\mathrm{D}_{2} \mathrm{O}$ spectra from 6000 to $0 \mathrm{~cm}^{-1}$. J. Chem. Phys., 131: 184505.

Michaelides A. \& Morgenstern K. (2007) Ice Nanoclusters at Hydrophobic Metal Surfaces. Nat. Mat., 6, 597-599. Mosin O.V. \& Ignatov I. (2011) Structure of water and physical reality. Soznanije i physicheskaja realnost, 10(1), 32-48 [in Russian].

Mosin O.V. \& Ignatov I. (2013a) The ice crystal riddles. Soznanije i physicheskaja realnost, 17(5), 21-31 [in Russian].

Mosin O.V. \& Ignatov I. (2013b) Structure of water. Chimija, 1, 12-32 [in Russian].

Nemukhin A.B. (1996) The variety of clusters. Russian Chemical Journal, 40(2), 48-56 [in Russian].

Ohno K., Okimura M., Akai N. \& Katsumoto Y. (2005) The effect of cooperative hydrogen bonding on the $\mathrm{OH}$ stretching-band shift for water clusters studied by matrix-isolation infrared spectroscopy and density functional theory. Phys. Chem. Chem. Phys., 7, 3005-3014.

Pasichnyk I. Everaers R. \& Maggs A.C. (2008) Simulating van der Waals-interactions in water/hydrocarbon-based complex fluids. J. Phys. Chem. B, 112(6), 1761-1764.

Pauling L. (ed.) (1960) The Nature of the Chemical Bond and the Structure of Molecules and Crystals. New York: Cornell University Press.

Petkov V., Ren Y. \& Suchomel M. (2012) Molecular arrangement in water: random but not quite. J. Phys. Condens. Matter, 24, 155102.

Pimentel G.C. \& McClellan A.L. (1960) The hydrogen bond (L. Pouling, Ed). New York: Reinhold Publishing Co.

Pople J.A. (1951) Molecular Association in Liquids: A Theory of the Structure of Water. Proceedings of the Royal Society, 205, 1081-1089.

Roy R (2004) A contemporary materials science view of the structure of water. In: Symposium on Living Systems/Materials Research, Boston: MA, Nov. 28, 2004.

Samoilov O.Ya. (1963) Studies of the structure of water. Journal of Structural Chemistry, 4(4), 459-461.

Sykes M. (2007) Simulations of RNA Base Pairs in a Nanodroplet Reveal Solvation-Dependent Stability. PNAS, 104(30), 12336-12340.

Saykally R. (2005) Unified Description of Temperature-Dependent Hydrogen Bond Rearrangements in Liquid Water. PNAS, 102(40), 14171-14174.

Timothy S. \& Zwier S. (2004) Chemistry: the Structure of Protonated Water Clusters, Science. 304(5674), 11191120.

Tokmachev A.M., Tchougreeff A.L. \& Dronskowski R. (2010) Hydrogen-Bond Networks in Water Clusters $\left(\mathrm{H}_{2} \mathrm{O}\right)_{20}$ : An Exhaustive Quantum-Chemical. European Journal of Chemical Physics And Physical Chemistry, 11(2), 384-388.

Tokushima T., Harada Y., Takahashi O., et all. (2008) High resolution X-ray emission spectroscopy of liquid water: The observation of two structural motifs. Chem. Phys. Lett., 460, 387-400.

Tsai C.J. \& Jordan K.D. (1993) Theoretical Study of the $\left(\mathrm{H}_{2} \mathrm{O}\right)_{6}$ Cluster. Chem. Phys. Letters, 213, 181-188.

Wang F \& Jordan K.D. (2003) A Parallel Tempering Monte Carlo Investigation of $\left(\mathrm{H}_{2} \mathrm{O}\right)_{6}^{-}$. J. Chem. Phys., 119 , $11645-11653$.

Wernet Ph., Nordlund D., Bergmann U., et all. (2004) The structure of the first coordination shell in liquid water. Science, 304, 995-999.

Walrafen, G.E. (1972) Raman and infrared spectral investigations of water structure. In Water a Comprehensive Treatise, F. Franks, Ed., Vol. 1, Plenum Press, New York, pp. 151-214.

Zenin S.V. (1999) Structured water condition as a basis for controlling the behavior of living systems and safety. Diss. Doctor Biological Sciences. Moscow: Institute of Medical Biological Problems [in Russian].

Yamaguchi Y, Yasutake N. \& Nagaoka M. (2001) Theoretical prediction of proton chemical shift in supercritical water using gas-phase approximation. Chem. Phys. Lett., 340, 129-136.

Yukhnevitch, G.B. (1973) Infrared spectroscopy of water. Moscow, Nauka, 207 p. [in Russian].

Zelsmann, H.R. (1995) Temperature dependence of the optical constants for liquid $\mathrm{H}_{2} \mathrm{O}$ and $\mathrm{D}_{2} \mathrm{O}$ in the far IR region. J. Mol. Struct., 350: 95-114. 